\title{
Managing innovation in English language education
}

\author{
Alan Waters Lancaster University, UK \\ a.waters@lancaster.ac.uk
}

Innovation in English language education (ELE) has become a major 'growth area' in recent years. At the same time, an ELE innovation management literature has also developed, based on insights from innovation theory and their application, both from outside and within ELE, and concerned with attempting to critically evaluate and inform ELE innovation practice. Thus, using a well-established three-part framework for distinguishing the main stages involved in innovation project management, this review describes and discusses the main features of this body of work. After defining terms and clarifying its scope, it considers what is said about the innovation 'initiation' phase, in terms of innovation causes, characteristics and contexts. It then examines conceptualisations of the innovation 'implementation' stage, by distinguishing main overall approaches, frameworks for identifying and configuring roles, underlying psychological processes, and the use of evaluation techniques. Lastly, the literature relating to innovation 'institutionalisation' stage is analysed. The article concludes by identifying overall trends and areas for further development. In particular, it is argued that ELE innovation work needs to become more informed by many of the concepts and procedures which the ELE innovation management literature contains.

\section{Introduction}

\subsection{Rationale}

'Innovation' - the attempt to bring about beneficial change (West \& Farr 1990: 9) - has become a defining characteristic of English language education (ELE) over the last twenty years or so, as a glance at compendiums of activity such as Carter \& Nunan (2001) testifies. At the same time, from the second half of the 1980s, a literature has emerged within ELE which has attempted to ally this multiplying rate of change to an understanding of innovation theory and practice. As will be seen, much of it has been motivated (i) by evidence that innovation in ELE, despite its recent exponential increase, has often been less successful than intended, and (ii) as a corollary, by the development of the view that greater effectiveness might be achieved by a more informed understanding of the large body of work on innovation which exists outside ELE, and how it might be brought to bear on the design and implementation of innovations within ELE. It is the purpose of this review to attempt to describe and critically evaluate this literature. This will be done by first of all clarifying the nature 
of the main concepts under focus, indicating the scope of the review, and outlining its structure.

\subsection{Definitions, scope and structure}

The terms 'innovation' and 'change' can be used as equivalents, both referring, somewhat indeterminately, to ideas such as 'difference' or 'novelty'. The ELE innovation literature, however, sometimes reflecting some of the competing definitions and conceptual distinctions made in the wider literature, contains a number of different views on the extent to which each of the two terms can and should be distinguished (see e.g. White 1988: 114; De Lano, Riley \& Crookes 1994: 488-489; Markee 1997: 47; Kennedy 1999a: iv). ${ }^{1}$ More recently, though, Lamie (2005: 7), while principally concerned with 'innovation', uses the term 'change' in the book's title; in Murray (2008a) the terms are used synonymously; and in Wedell (2009: 1) they are seen as equivalents. In what follows, therefore, the two terms will also be used interchangeably, unless specified otherwise.

In terms of scope, it has not been possible, because of the practicalities involved, to include literature written in languages other than English. Space limitations have also meant that, despite the obvious desirability of doing so, it has not been possible to include literature on innovation management concerned with the teaching of languages other than English. The items which have been focused on are therefore those written in English and concerned with the application and development of an innovation theory perspective in relation to ELE. Of its nature, this literature is related predominantly to English as a foreign language (EFL) contexts outside Europe ${ }^{2}$ and the English as a second language (ESL) context in North America. In addition, for the same reason, many of the items with UK authorship, especially those from the 1980s and 1990s, are development aid project-based, and there is relatively little coverage of 'local' educational change initiatives. Space constraints have also meant that reference to the wider literature on educational innovation has had to be confined to the parts of it which are shared with the ELE literature.

The structure of the review reflects the well-established overall conceptualisation of the educational innovation management process found in Fullan (2001b: 50-53). In this model (see Figure 1), 'three broad phases of the change process' are identified, as follows:

Phase I - variously labelled initiation, mobilization, or adoption - consists of the process that leads up to and includes a decision to adopt or proceed with a change. Phase II - implementation or initial use (usually the first two or three years of use) - involves the first experiences of attempting to put an idea or reform into practice. Phase III - called continuation, incorporation, routinization or institutionalization - refers to whether the change gets built in as an ongoing part of the system or disappears. (Fullan 2001b: 50)

\footnotetext{
${ }^{1}$ For the sake of clarity, references in this article to work by C. Kennedy are cited as 'Kennedy'. References to work by D. Kennedy and J. Kennedy are cited with the respective authors' initials.

${ }^{2}$ However, see Medgyes \& Malderez (1996) and Wedell (2009) for studies relating to Central and Eastern European settings; Morrow (2005) for the work of the Council of Europe, especially in connection with the Common European Framework; and regarding recent European developments in Content and Language Integrated Learning, see Klippel (2008).
} 


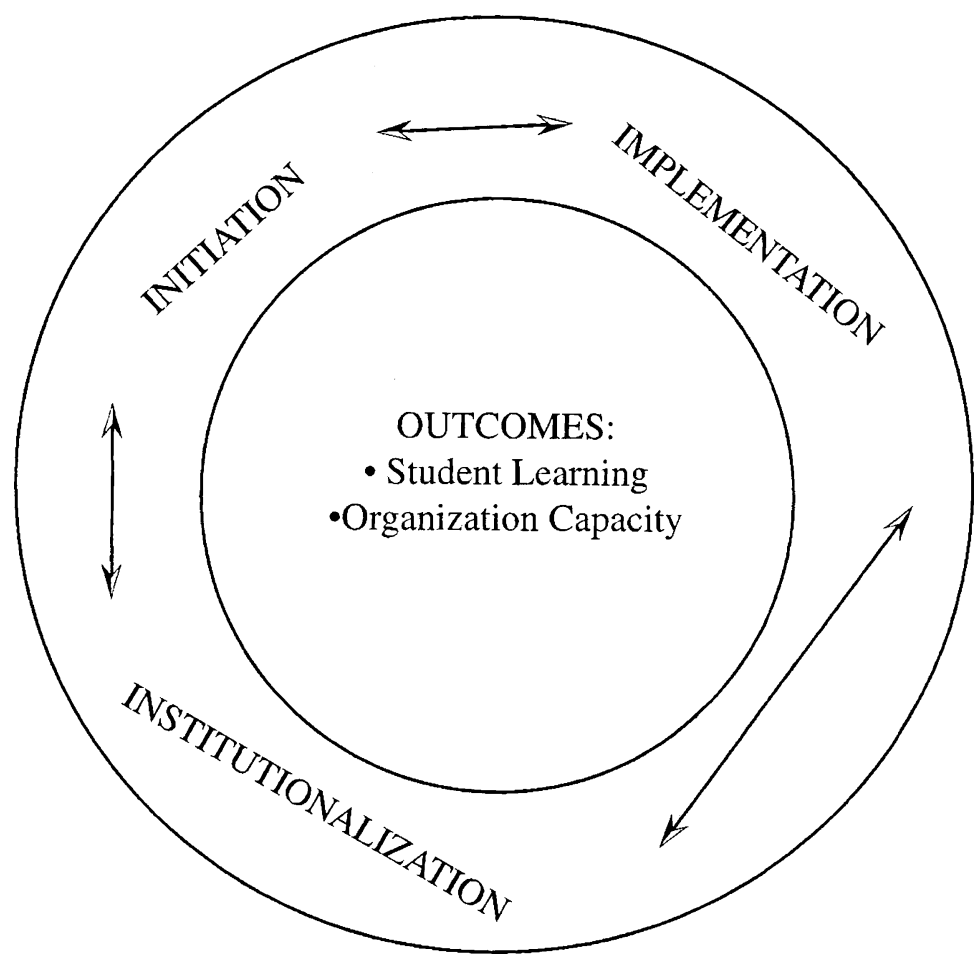

Figure 1 A simplified overview of the change process (Fullan 2001b: 51).

Thus, the review begins by focusing on the ELE literature relating to innovation INITIATION, identified as consisting principally of parts concerned with conceptualising (i) rationales for innovation, (ii) innovation characteristics, and (iii) innovation contexts. This is followed by a section on the main features of the ELE literature regarding innovation IMPLEMENTATION. It starts by considering the ways in which innovation implementation approaches have been conceptualised, i.e., models for attempting to bring about change; it then focuses on how various types of innovation participants have been distinguished; next, it moves to the parts of the literature concerned with conceptualisations of psychological processes in innovation implementation, i.e., the ways in which innovations are typically experienced and perceived by those responsible for implementing them, particularly teachers; this is followed by a focus on what has been said regarding evaluation in innovation projects, consisting, first of all, of a review of approaches to determining overall innovation impact, and, secondly, a consideration of ways in which the monitoring of innovation development has been attempted. This is followed by the third main section, in which the literature relating to Phase III in Fullan's model - INSTITUTIONALIZATION, a concept often referred to in ELE innovation work as concerned with innovation 'sustainability' - is reviewed. Finally, the review closes with a further section, in which the overall picture evinced by the earlier parts is delineated, 
and the implications for further research and theorising in ELE innovation management considered.

Before proceeding, however, it is important to also take heed of Fullan's warning that Figure 1

presents only the general image of a much more detailed and snarled process. First, there are numerous factors operating at each phase. Second, as the two-way arrows imply, it is not a linear process but rather one in which events at one phase can feed back to alter decisions made at previous stages, which then proceed to work their way through in a continuous interactive way. (Fullan 2001b: 50)

In what follows, therefore, it needs to be borne in mind that dividing the review into main sections corresponding to those in the outer circle in Figure 1 oversimplifies a much more complex and interactive reality. In other words, as with so many of the concepts and their application this review is concerned with, the whole needs to be seen as very much more than the sum of the parts. Nevertheless, such an arrangement has the advantage of providing a framework which can be seen as mirroring the overall sequence of events underlying the (ELE) innovation management process itself, thus providing a means of connecting the strands of the ELE literature on the topic into a reasonably coherent 'story-line', and so, despite its limitations, has been regarded as an appropriate organising principle.

\title{
2. Innovation initiation
}

Wall (1996), drawing on Fullan \& Stiegelbauer (1991: 50), summarises the concerns which the ELE innovation initiation stage can involve as follows:

\begin{abstract}
A number of questions need to be asked during this phase, relating to the origin and quality of the innovation, who has access to information, whether there is advocacy from central administration, whether there is teacher advocacy, the role of external change agents, the existence and nature of funding, and whether the orientation of the intended users of the innovation is 'problem-solving' or 'bureaucratic'. (Wall 1996: 339)
\end{abstract}

The ELE literature on the topic can be seen as focusing on two of these areas of concern, i.e., (i) the reasons why ELE innovations tend to be advocated, and (ii) characteristics affecting the quality of ELE innovations. It also encompasses a third aspect, namely the ways in which contextual variables in ELE innovation activity can be conceptualised.

\subsection{Innovation rationales}

Kennedy (1988: 336), drawing on the work of Kelly (1980), points out that a primary motivation for successful innovation is dissatisfaction with the status quo. Kennedy (ibid) also observes, however, that the degree of dissatisfaction is rarely spread evenly among the 
various parties involved, and its causes may likewise vary, a situation calling for negotiation and compromise in terms of any ensuing innovation. In addition, as Cooper (1989: 34-35) argues, it is important to distinguish between what may appear to be an immediate and obvious source of dissatisfaction with the status quo, and the presence of less overt and tangible but potentially more important overall drivers of change - ones, for example, of a political, economic or scientific nature.

A second major dimension in conceptualising rationales for innovation in ELE is to do with impetus for change. Thus, Henrichsen (1989: 3) draws on the typology of social change presented in Rogers \& Shoemaker (1971: 8) in order to analyse innovation in ELE in terms of whether (i) the potential source, and (ii) the recognition of the need for change are internal or external to the 'social system'. The resulting matrix gives rise to four main types of social change: IMMANENT CHANGE (internal source and recognition of need), SELECTIVE CONTACT CHANGE (external source, internal recognition of need), INDUCED IMMANENT CHANGE (internal source, external recognition of need) and DIRECTED CONTACT CHANGE (external source and recognition of need).

Markee (1997: 48-49) argues that these four types of change form a cline in terms of the potential level of innovation adoption they are likely to result in, with the first being deepest, the next two forming an intermediary level, and the fourth typically being the shallowest. He also points out that, although 'immanent change' is the kind most often discussed in the wider literature, it rarely occurs in practice. 'Selective contact change' occurs when, for example, a textbook originally intended for use in one situation is adopted in another, different one. An example of 'induced immanent change' is documented in Kennedy (1987), where the author, in his role as an external consultant, facilitated insiders' efforts to innovate in their own, preferred directions. Henrichsen (1989) sees the US-sponsored English Language Exploratory Committee (ELEG) project - which attempted to introduce audio-lingualism into the Japanese educational system during the 1950s and the1960s - as an example of directed contact change, and argues that, because of its global nature, much other innovation work in ELE can be similarly characterised, while Markee (1997: 49) sees many ELE development aid projects as also falling into this category.

A further conceptualisation of factors affecting large-scale change in ELE in particular, ones derived mainly from wider changes in educational thinking and practice, is found in Wedell (2009: 14-16):

1. to enable the national educational system to better prepare its learners for a changing national and international reality

2. to make the education system more clearly accountable for the funding it receives

3. to increase equality of opportunity within society as a whole

4. to use the announcement of educational changes for some kind of short-term political advantage

The last of the items in this list relates specifically to the role of 'extraneous' factors in motivating change in ELE. As Richards (1984: 13) points out, ' $[\mathrm{t}]$ he rise and fall of methods depends upon a variety of factors extrinsic to a method itself and often reflects the influence of fads and fashions, of profit-seekers and promoters, as well as the forces of the intellectual 
marketplace' (see also Fullan 2001b: 53). As instances of such factors, Richards mentions (inter alia) the effect of an innovation appearing in textbook form, the marketing efforts of publishers, and promotion by organisations such as the British Council. Similarly, as argued by, for example, Pennycook (1994), Canagarajah (1999) and Holliday (2005), many ELE innovations can be seen as being advocated because of the global hegemonic influence of 'Anglophone cultural discourse', i.e., in order to advance the socio-political interests emanating from this quarter, rather than because of the benefits that they are claimed to provide. Waters $(2007,2009 \mathrm{~b})$, on the other hand, see the advocacy of a number of other recent innovations, such as the use of non-metropolitan models of English as a basis for syllabus design (Matsuda 2006), as resulting from a 'critical theory'-based counterhegemony originating within the ELE professional discourse itself. In all cases, in other words, it seems clear that factors other than purely educational ones also affect the genesis of many ELE innovations. It also appears likely that a number of additional factors are also involved, even though the ELE innovation literature tends to have less to say about them, such as the effects of significant changes in organisational structures and personnel (Parsons \& Fidler 2005; Alderson 2009) and the role of commercial pressures (see section 3.1 below).

Given the competing nature of rationales for innovation in ELE, it is appropriate to conclude this section with a further extract from the summary in Wall (1996) of what Fullan \& Stiegelbauer (1991: 50-56) regard as major issues to do with motivations for innovation initiation:

Fullan states that when an innovation fails, there is a tendency to blame the way it was implemented rather than criticize the idea itself. He insists that the source... of innovations should always be investigated before they are put forward for adoption. Would-be innovators should ask themselves questions like the following:

- Where did the idea for change come from? From a teacher, or a group of teachers? From an academic? From a politician?

- What was the motivation behind the idea? Was it to solve a problem which practitioners agreed needed solving? To test out a theory? Or to take advantage of opportune funding?

(Wall 1996: 339)

\subsection{Innovation characteristics}

A second main factor affecting the initiation of innovations in ELE evinced by the literature relates to the design features that innovations can have, and their effects (positive and negative) on potential for adoption. Several authors (e.g. White 1988: 140-141; Henrichsen 1989: 8286; Markee 1997: 59-61) mention the set of innovation characteristics described in Rogers (1983), which, on the basis of a study of a large number of different types of innovations, were identified as likely to enhance or reduce the possibility of adoption. In their most recent formulation, these characteristics are as follows:

ReLative adVANTAge: the degree to which an innovation is perceived as better than the idea it supersedes... 
Compatibility: the degree to which an innovation is perceived as being consistent with the existing values, past experiences and needs of potential adopters...

COMPLEXITY: the degree to which an innovation is perceived as difficult to understand and use ...

TRIALABILITY: the degree to which an innovation may be experimented with on a limited basis...

OBSERVABILITY: the degree to which the results of an innovation are visible to others.

(Rogers 2003: 15-16)

All of these features are seen by Rogers to correlate positively with the potential for an innovation to be adopted, except for the 'complexity' factor. A further criterion identified by Rogers - one that is also regarded as correlating positively with potential for adoption - is that of 're-invention', i.e., 'the degree to which an innovation is changed or modified by a user in the process of adoption or implementation' (Rogers 2003: 16; also 180-188). However, despite its obvious potential relevance to the innovation 'institutionalization' phase in particular (see Watson Todd 2006, and section 4 below), this characteristic has not been discussed in the ELE literature to the same extent as the others.

Henrichsen (1989: 82-86) mentions a number of additional characteristics that ELE innovations may possess, such as Originality (the greater the originality, the lower the potential for compatibility), Explicitness (the more concrete the innovation, in terms of its underlying principles as well as its practical procedures, the higher the likelihood of adoption), and Status ('association with a higher social level' (p. 85) and the consequent potential for making the innovation appear more attractive). Kennedy (1988: 336-337) describes the three main criteria that Kelly (1980), on the basis of his research into the implementation of a major UK social sciences curriculum reform initiative, found teachers used in order to determine whether a proposed innovation was seen to match their working contexts sufficiently closely. The first such factor was 'feasibility' - the extent to which the innovation was seen as capable of being put into practice. The second was 'acceptability' - the degree to which the innovation was regarded as compatible with teachers' educational beliefs and teaching approaches. The third was the amount of 'relevance' the innovation was perceived to have - i.e., whether it was felt by the teachers to meet the needs of their learners. The greater the perceived match between all three criteria, the greater the likelihood of the innovation being adopted (and vice versa).

Finally, via a meta-analysis of variables such as those above, Stoller (1994) provides a further conceptualisation of ELE innovation features affecting potential for success or failure. Her survey of innovations in US higher education Intensive English Programs (IEPs) showed that three main Factors pertaining to innovations had the greatest potential to affect their adoption. The more prominent the presence of two of these - the Dissatisfaction Factor and the Viability Factor - the stronger the likelihood of innovation adoption. The third - the Balanced Divergence Factor (consisting of e.g. Explicitness, Complexity and Originality) was also found to positively affect potential for adoption IF the overall zONE OF INNOVATION represented by the constituent attributes conformed to the Goldilocks Principle, i.e., so long as its size was neither too small nor too large, but 'just right'. It needs to be borne in mind, however, that IEPs, of their nature, may have a greater propensity towards innovation than other kinds of ELE programmes. 


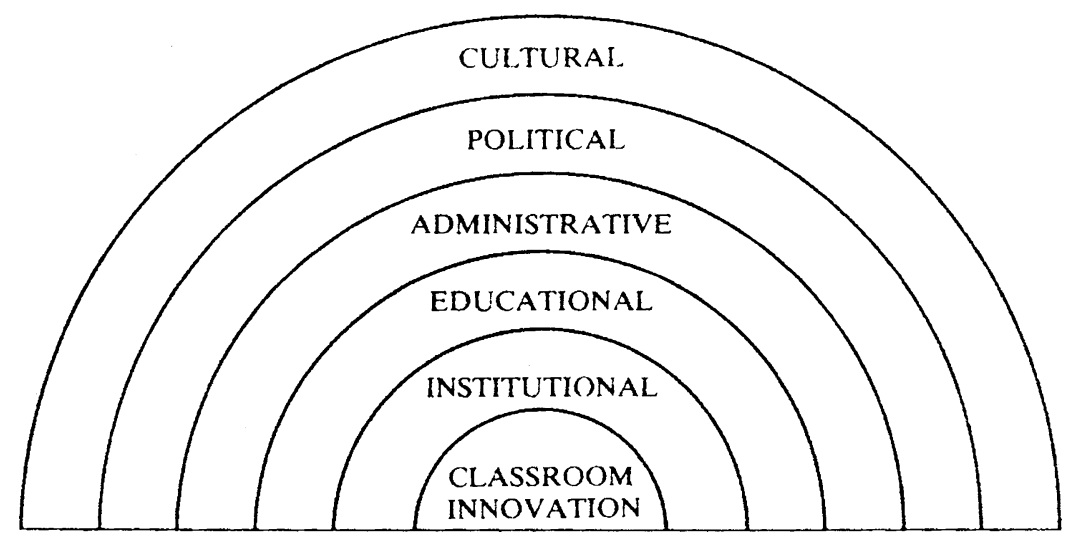

Figure 2 The hierarchy of interrelating subsystems in which an innovation has to operate (Kennedy, 1988: 332).

In Henrichsen (1989), the ELEG project (see section 2.1 above) is analysed in terms of (inter alia) a combination of Rogers' and his own set of innovation characteristics. Similarly, using a number of the above criteria, Markee (1997) analyses a range of major ELE innovations, such as 'the notional-functional syllabus', 'the natural approach' and 'task-based language teaching' (TBLT), in order to identify the charcateristics of each of them which can be seen to either help or hinder their adoption. Thus, for example, TBLT is regarded as having features, in terms of the 'feasibility' and 'compatibility' criteria, which are in some respects potentially positive and in others potentially negative, and, as far as its 'relative advantage' in foreign language contexts is concerned, largely negative (Markee 1997: 35-39). A similar analysis is made with respect to the attributes of the 'curricular and teacher innovation' (CATI) project, the detailed ELE innovation case study which makes up Part II of Markee's book (see pages 89-93 in particular).

However, despite these and a few other contributions to the ELE literature on the topic (such as Bax 2003), there is very little direct or indirect reference to innovation characteristics elsewhere in the literature on ELE innovation. Rather, it is all too easy to identify instances of ELE innovation projects where lack of success, at least in part, can be associated with a failure to take this dimension adequately into account, such as those described in, for example, Kouraogo (1987), Henrichsen (1989), Tomlinson (1990), Lamb (1995), Shamim (1996), Karavas-Doukas (1998), Li (1998), D. Kennedy (1999), Carless (2002), Nunan (2003) and O'Sullivan (2004). Such a state of affairs indicates the need for a greater understanding of this aspect of innovation theory in ELE innovation activity.

\subsection{Innovation contexts}

Probably the best-known and most influential overall theoretical framework concerned with conceptualising ELE innovation contexts is to be found in Kennedy (1988: 331-334), and is shown in diagrammatic form in Figure 2. Each of the arcs in the figure represents a 
'sub-system' of the innovation context as a whole. The arcs are seen as being in a hierarchical relationship, 'with the outer rings being the more powerful and influencing the inner rings' (p. 332). Thus, the 'cultural' sub-system is seen as exerting a strong influence on the nature of the 'political' and 'administrative' sub-systems, which in turn shape the nature of the 'educational' sub-system, and thus the characteristics of teaching institutions and what happens in the classrooms which they contain (cf. 'STEP' and other similar systems (Bowers 1994), which attempt to analyse operational environments in terms of scientific, technological, economic, political and other trends).

The possibilities for innovation at the classroom level are therefore seen to be determined to a great extent by the remainder of the contextual system. Kennedy also argues that if an innovation manager is ignorant of the relevant contextual factors, or is aware of them but tries to ignore or change them, then problems are likely to arise, since the innovation may be viewed as not fitting in well enough with existing norms (p. 333) (cf. Rogers' (2003) 'compatibility' characteristic in section 2.2 above). Markee (1997: 9-15) provides a particularly graphic illustration of such an eventuality, in relation to a UK ELE development project in the Sudan. Also, the 'directed contact' type of change that tends to predominate in ELE, as discussed in section 2.1 above, has probably made it particularly prone to this problem, and numerous other examples of lack of fit between the design features of ELE innovations and their contexts of implementation can be found in the literature (see e.g. Tomlinson 1990; Holliday 1994a; Shamim 1996; Carless 1997; Karavas-Doukas 1998; Li 1998; Hu 2002).

However, Kennedy's framework is criticised in Markee (1997: 56) for not being value-free, for lending support to cultural stereotypes of learners, and for giving the impression that only the outermost sub-system is 'cultural' in nature. Also, a number of refinements to and extensions of the model are discussed in C. Kennedy \& J. Kennedy (1996) and J. Kennedy \& C. Kennedy (1998). In the first (cf. D. Kennedy 1999), drawing on Ajzen's (1988) THEORY OF PLANNED BEHAVIOUR, it is shown that the potential for an innovation to be adopted in a given context is not simply a function of its prevailing ethos but also of subjective factors relating to individual perceptions of self-agency, a perspective illustrated with reference to attempts to bring about changes in teachers' error correction practices and general methodological approach (see also section 3.3 below).

In J. Kennedy \& C. Kennedy (1998), it is seen as important, when analyzing contextual factors, to adopt an 'interpretative' perspective (one based on individuals' 'accounts and perceptions of the change processes in which they are involved and the discourse events which occur during the period of change' (p. 457)) and not just a 'structuralist' one (i.e., based on an analysis of roles, relationships, and change processes, resulting in a set of cultural 'categories', as in e.g. Hofstede 1991). In other words, the use of both 'emic' as well as 'etic' understandings of cultural behaviour is advocated. It is argued that the addition of an interpretative angle can reveal important exceptions to the overall picture provided by an exclusively structuralist view. Thus, for example, as the authors show, the concept of 'collaboration' can be seen from certain cultural perspectives to be compatible with a relatively top-down discourse, and classrooms in a generally group cooperation-oriented culture can operate an individually-competitive micro-culture. Such an approach would therefore seem to go some way towards answering Markee's criticisms, i.e., conceptualisation in this area needs to consider what contextual features are actually oriented to by 'stakeholders' themselves, and how they interpret them. 
The importance of attempting to understand innovation contexts from an emic or 'ethnographic' perspective is given particular prominence in Holliday (1992, 1994a, b, 1996a, 1999). Thus, for example, Holliday (1994a) argues that (innovation) management 'cannot provide answers for WHAT to manage...the key area is still lacking: we still do not have enough data about what really happens in the classroom between people' (p. 10). Remedying this lacuna is seen to involve looking not only for the right information within classrooms, but 'around' them as well, particularly in order to identify the values and patterns of behaviour of the various types of social groupings which can influence 'classroom culture'. Such INFORMAL ORDERS (Holliday 1992), i.e., unofficial but actual patterns of behaviour, perceptions and so on, and SMALL CULTURES (Holliday 1996b) (as distinct from structuralist conceptualisations of 'large', national-level cultural tendencies) are seen to include student, host institution, professional-academic and international education-related values and norms.

Thus, in Holliday (1994b: 12), a distinction is made between the ethos of two main types of ELE teaching institutions, those of the 'BANA' variety (located mainly in Britain, Australasia and North America) and of the 'TESEP' kind (tertiary, secondary and primary, and state education bodies located throughout the ELE 'world'). It is argued that, the former, the purpose of ELE is primarily 'instrumental', whereas in the latter it is mainly 'institutional'. As a result of these and a number of other mutually differentiating features, the two types of institutions are seen to represent alternative 'cultural' tendencies, which influence the potential for different kinds of teaching methodologies to be operated in them. Thus, a teaching approach which might be regarded as appropriate to a BANA setting is seen as potentially problematic in a TESEP one, and vice versa.

Similarly, and like their counterparts in other subject areas, ELE teachers are also seen to be influenced by their adherence to the values of either the COLLECTIONIST or the INTEGRATIONIST 'professional-academic' paradigms (Holliday 1994a). These 'teaching cultures' are regarded as differing from each other in terms of a number of major dimensions. For example, the former is characterised as favouring a pedagogy which is 'didactic, content-based' and the latter is 'skills-based, discovery-oriented, collaborative' (p. 72). The professional-academic culture of TESEP teachers is seen as primarily 'collectionist', and that of BANA teachers as predominantly integrationist (pp. 73-74). However, as acknowledged in Holliday (2005: 2-4), such distinctions suffer from conceptual and other forms of overlap, especially as a consequence of increasing globalisation, and therefore need to be interpreted cautiously, as a means of aiding identification of the specific characteristics of individual institutions, rather than a ready-made 'template' (Holliday 1994b: 5).

A further conceptualisation of innovation contexts, this time at the educational 'subsystem' level, is found in Clark (1987). Drawing on Skilbeck (1982), Clark identifies three main educational 'value systems', namely, CLASSICAL HUMANISM, RECONSTRUCTIONISM and PROGRESSIVISM, corresponding to a pedagogical focus on what might be seen as, respectively, 'input', 'skills' and 'process'. In ELE terms, representative examples of methods associated with each of the systems are, respectively, the grammar-translation approach, the 'weak' version of the communicative approach (Howatt 1984: 279), and the natural approach (Krashen \& Terrell 1988). Successful curriculum renewal is seen by Clark (1987) as dependent 
on (inter alia) achieving an integrated and balanced amalgam of the attributes associated with all three tendencies (cf. Finney 2002).

Another main contextual variable discussed in the literature - and, once again, one which contains the seeds for potential innovation conflict - is that of 'organisational cultures'. White (1988: 136-139) points out that '[s]chools, as organizations, constitute the major context in which innovations will be installed, so it is worth giving some attention to the culture of organizations, especially as organizational culture, innovation strategy and models of innovation will probably be interrelated'. Following Handy (1984), White 1988 discusses four main types of organizational 'culture': Club or Power, Role, TASK and Person. Briefly, the structure of the first resembles a spider's web, with power concentrated in the hands of a central authority figure, and is found in, for example, owner-run language schools. The second is hierarchical in nature, with well-defined sets of roles and responsibilities governing working procedures. Secondary schools, in particular, are likely to have a structure of this kind. The third involves a team-oriented, collaborative, problem-solving structure, centring round a particular job or project. An innovation project team will often be organised along such lines. Finally, the fourth type of culture consists of a relatively looselyorganised collection of individuals, and involves minimal formality in terms of agreed working procedures. Academic departments in UK and US universities usually have this kind of structure.

White (1988: 137) also points out that '[f]ew organizations are restricted to only one culture', although, it might also be added, one of them usually predominates. In addition, variants may also exist. Thus, for example, an owner-run language school CHAIN may take on characteristics associated with a role culture. There may also be covert centralising modus operandi at work in person-oriented organisational cultures. The categories are therefore best seen as heuristics, like others already discussed, out of which more refined, individualised conceptualisations can be developed. From an innovation management perspective, White explains that among the corollaries arising from the existence of different organisational cultures of these kinds are (i) that innovation is more likely to take place in 'task-' and 'person'-oriented cultures than 'role'-oriented ones, and (ii), that each can be associated with a preferred innovation 'strategy' (p. 138) (see section 3.1 below). Thus, the potential for conflict between, for example, the role-based organisational culture typical of educational institutions and the task-based culture associated with innovation 'units' is obvious (cf. J. Kennedy \& C. Kennedy 1998: 462-464). The Sudan ELE development aid project described in Markee (1997: 9-15) also serves as a clear illustration of this problem.

Finally, Henrichsen (1989: 79-94), as part of his HYBRID MODEL of innovation diffusion (for a convenient overview, see White et al. 1991: 180-188), identifies a number of additional contextual factors affecting innovation management. First of all, because of the way they are seen as likely to affect any further potential innovation efforts, the model includes a component concerned with analysing the main contextual ANTECEDENTS of the innovation situation. This 'focuses attention on the historical nature and development of these factors and reminds reformers of the necessity of investigating them as part of the planning process' (p. 79). Then, in the PROCESS section of the model, provision is made for the analysis of Factors which Facilitate/Hinder Change in the innovation context, as they occur Within 
the Innovation Itself (cf. section 2.2 above), Within the Resource System, Within the User System, and so on.

Henrichsen demonstrates how such a system of analysis throws extensive light on the causes of failure of the ELEC initiative. The model is also used in Wall (2000: 504-506) (see also Wall 1999, 2005) to investigate causes of problems in a Sri Lankan ELE innovation testing project, and in Kinzley (in progress), in order to study Chinese undergraduates' experiences in attempting to master new EAP/study skills in the UK university context. However, despite the Hybrid Model's sophisticated analytical 'machinery', both the model itself and many of its categories do not seem to have diffused throughout the ELE literature in the way they might have (due at least partly, perhaps, to the scarcity and cost of the book in which they are described). Also, in overall terms, much the same point can be made with respect to many of the other concepts reviewed in this section. In other words, despite the relatively long-standing and well-developed literature concerning contextual factors in ELE innovation management, it can be argued that it is still the case that too much ELE innovation activity fails to adequately take its implications into account, as many of the reports in even such recent volumes as Murray (2008b) testify, such as Adamson \& Davison (2008), Godfrey et al. (2008) and Katz, Byrkun \& Sullivan (2008), as well as the case studies in Wedell (2009: section 2).

In concluding this section it therefore seems worthwhile drawing attention to the overall framework provided in Wedell (2003) for attempting to avoid this problem (cf. Wedell 2009: section 3), one which puts accounting for contextual variables at the heart of the ELE innovation initiation process, and links their identification closely to the practical implications for ELE innovation management as a whole. Viewing 'ESOL curriculum change as cultural challenge' (Wedell 2003: 441), it is argued that

to support teachers through the TESOL curriculum change process planners need to explicitly consider the implications of their plans from two interdependent points of view. Firstly they need to try and identify the degree of cultural shift that the practices implied by the proposed changes will represent for most teachers, and so what sort of support will be needed by whom for how long, to help teachers make the transition. Secondly, they need to consider what imbalances the proposed curriculum changes may introduce among other influential components of the language education system, and so what adjustments will be required, when [sic], to restore balance and so support the introduction of new practices. (Wedell 2003: 447-448)

As a consequence, it is seen as important for 'curriculum change planners' to ask and attempt to answer two sets of main questions; firstly,

- [W] hat degree of cultural shift do the project objectives as initially articulated imply, and/or what fundamental cultural values might the objectives threaten?

- [W] hat specific support might teachers need, to be able/willing to accommodate such a shift?

and secondly (and consequently),

- $[\mathrm{H}]$ ow can teachers' work in the changed TESOL classroom be supported by other factors which influence teachers' working environments?

- $[\mathrm{W}]$ hat will providing such support imply for the funding, timing and sequencing of the curriculum change process?

(Wedell 2003: 448) 
Both these sets of main questions are subsequently broken down into further, more specific ones (pp. 449, 451), in order to indicate the level of practical support seen as necessary for effective ELE innovation management. Finally, the process as a whole is summed up in an overall algorithm entitled 'Planning language development projects to support Key Players' (pp. 452-453).

\section{Innovation implementation}

This section of the review encompasses the parts of the literature concerned with attempting to put the outcomes of the innovation initiation phase into practice - the process of innovation implementation.

For the sake of clarity, it is divided into several sections, beginning with a review of implementation approaches, i.e., overall conceptualisations of implementation process management; it then considers the ways in which the 'figures in the landscape' of innovation implementation - innovation participants - have been identified; next, the spotlight is on how various psychological processes in innovation implementation have been conceptualised, especially as these can be seen to impact on the teacher, usually the main front-line implementer; the focus then moves on from, so far, an overall concern with trying to answer the question 'How might innovation implementation be attempted?' to the related issue of trying to determine how effective the implementation process has been and how it can be adjusted, as necessary, on an ongoing basis, - in other words, to a consideration of what has been said regarding methods for the evaluation of innovation impact and about the ways in which monitoring of innovation development can occur.

\subsection{Implementation approaches}

On the basis of information in, for example, White (1988), Henrichsen (1989), Markee (1997), Lamie (2005) and Wedell (2009), Table 1 below attempts to provide an overview of, first of all, the main innovation implementation models that can be discerned, secondly, of the change strategies (Chin \& Benne 1970) that can be associated with each of them, and finally, of some of the types of ELE innovations that illustrate their application in practice. It should be noted, however, that, in the interests of clarity, the picture presented is an oversimplification, and in reality there will usually be overlap and interaction between its various 'cells'.

Within ELE, as Markee (1997: 63-64) indicates, there has been a tendency for the first two approaches (A and B) to predominate, with the former being preferred by political systems, and the latter being the 'weapon of choice' of applied linguistics. Both involve an underlying centripetal, dissemination dynamic, the main difference being the more staged, systematic overall structure typically employed by the latter. With reference to approach A in particular, Kennedy (1999b: 1) says: '[t] here seems little alternative to a top-down approach when changing national systems of education if there is to be an attempt at some form of uniformity and standardization in teaching and assessment across schools', although he also 
Table 1 Models of change, change strategies and ELE innovations.

\begin{tabular}{lcc}
\hline \hline Approach & Model & Associated strategies
\end{tabular}

A CENTRE-PERIPHERY: The prestige and/or power of the innovation centre influences/forces the adoption of the innovation - a variation on the $\mathrm{R}$ D \& D model (see below).

RESEARCH, DEVELOPMENT AND DIFFUSION ( $R$, D \& D) (Havelock 1969: 11, 5-7): Similar to the Centre-periphery model above, but based more on a process of scientific, systematic working-out. Problem-SOlving (Havelock 1969: 11, 11-15): Main difference from the other models is that the innovation process centres on the 'problem-owner' rather than being controlled primarily by outside agencies/individuals. SOCial INTERACTION (see e.g. Havelock 1969: 11 , 7-11): Emphasises the role that social relations play in the spread of an innovation. It thus adds the dimension of social context to the picture rather than constituting a further model (Markee 1997: 62).

E LinkagE: Markee (1997: 68) describes this as a 'contingency' view of innovation, i.e., the idea that the best model(s) to use will depend on the innovation situation in question. However,

Havelock (1969: 11, 17) characterises its essence as involving the formation of important reciprocal linkages (channels) between (i) the 'user system' and the immediate 'resource system', and (ii) the immediate 'resource system' and more remote resources (see Figure 3).
Power-coercive (P-C): The use of legislation and other sanctions to

\section{force change to occur.}

Rational-EMPIRICAL (R-E): The use of reason and other forms of evidence to show the need for change.

\section{P-C}

R-E

Normative-Re-EDUCATIVE (N-R): Bringing about change through collaborative problem-solving.

Overtly R-E, covertly P-C, and sometimes $\mathrm{N}-\mathrm{R}$ ?

Potentially, an integrated and balanced blend of P-C, R-E and $\mathrm{N}-\mathrm{R}$.
Most reforms initiated by governments, aid agencies in developing countries (see e.g: Markee 1997: 9-15) and other large, centralised organisations. For illustrations, see e.g. Karavas-Doukas (1998), Carless (1999), Goh (1999), Waters \& Vilches (2008). Applied linguistics-promoted approaches, for example, Audio-lingualism, the Communicative Approach, and Task-based Learning. See e.g. Henrichsen (1989).

Action research, 'appropriate methodology' (Holliday 1994a), 'exploratory practice' (Allwright \& Lenzuen 1997), the 'reflective practitioner' approach to teacher development (Wallace 1991).

Any innovation spread by e.g. conferencing, associationism, informal networking, journals, books, web-sites, courses, and other workings of the 'professional discourse'.

See e.g. Breen et al. (1989), Waters (1997); the CATI project (Markee 1997: Part II), Goh (1999); the PELT Project (Waters \& Vilches 2001).

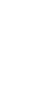

.


goes on to stress the importance, in such an approach, of the presence at an intermediate level of a 'change agent' (see section 3.2 below), i.e., someone 'responsible for the implementation of the change' (p. 2); (see also Goh 1999).

However, a good deal of the literature has also highlighted the problems associated with both approaches, especially those of lack of ownership and contextual fit (see e.g. Breen et al. 1989; Lamb 1995; Shamim 1996; Markee 1997; Karavas-Doukas 1998; Goh 1999; O'Sullivan 2004; Godfrey et al. 2008). Both are seen to be based on an 'objective', 'one size fits all' view of change, and therefore tending to downplay or ignore the importance of the way it is ultimately experienced and made meaningful on a subjective basis at the individual and group levels (see Hutchinson 1991; see also Fullan 2001b; Trowler 2003; and section 3.3 below).

Of the other three, approach $\mathrm{C}$ has increasingly formed the basis of numerous relatively small-scale, local initiatives, particularly well-documented examples being Kennedy (1987), Breen et al. (1989), Holliday (1994a), Williams \& Burden (1994) and Allwright \& Lenzuen (1997). It is seen as providing a solution to the main problem inherent in the first two approaches, because of its emphasis on the involvement and engagement of the 'end-user' in the development and implementation of the innovation (Lamie 2005: 19-20). However, it has yet to find favour with larger-scale, regional or national-level educational reforms in the same way as approach A, perhaps because of a perceived tendency for it to focus too exclusively on only the 'problem-owner' perspective (Havelock 1969: 11, 13-14), in contradistinction to the more top-down style of innovation management typically associated with the organisational and national cultures of the former (cf. Markee 1997: 176; Waters \& Vilches 2008, and section 2.3 above; but for an alternative approach, which attempts to integrate top-down with bottom-up perspectives, see Wedell 2009: 47-53).

Approach D comprises a multiplicity of communication channels revolving around individuals and groups in loosely-structured social systems. On the face of it, therefore, it is a relatively 'end-user'-based approach to innovation implementation. Nevertheless, it can be seen to be subject to pressures and influences from dominant social groups, thus making its underlying dynamic, in reality, a less formal and systematic version of that associated with approaches A and B. This process occurs in the ELE field via the workings of the 'professional discourse' (see section 2.1 above). The tendency, in other words, is for the ELE profession, like any other social grouping, to be configured differentially in terms of power relations, with ideas flowing in a relatively unidirectional manner from the dominant to the less dominant groups. Therefore, albeit in different ways, ALL of the above approaches can be viewed as primarily one-way in orientation.

Approach E, on the other hand, can perhaps be seen as the one with the greatest potential for bringing about the necessary impetus for large-scale change while simultaneously minimising at least some of the problems associated with approaches A and B. Thus, as Figure 3 shows, the Linkage Process model (Havelock 1969: 11, 16) consists of a focus, in the right-hand circle, via the Internal Problem Solving Cycle in The User System component, on the identification of problems from the end-user perspective. At the same time, in the lefthand circle, via the parallel Simulation of User's Situation cycle in The Resource System component, centralised and 'expert' resources are brought to bear on the attempt to solve the users' problems. Provision is also made for a similar connection to More Remote Resources (e.g. the advice of consultants), in order to further extend the range of possible solutions that 
are attempted. The provisional solutions are then sent to the user system to be tried out and evaluated. As a result of the back and forth cycles involving experimentation on the basis of different 'problem' and 'solution' messages, suitable innovations are gradually developed and refined.

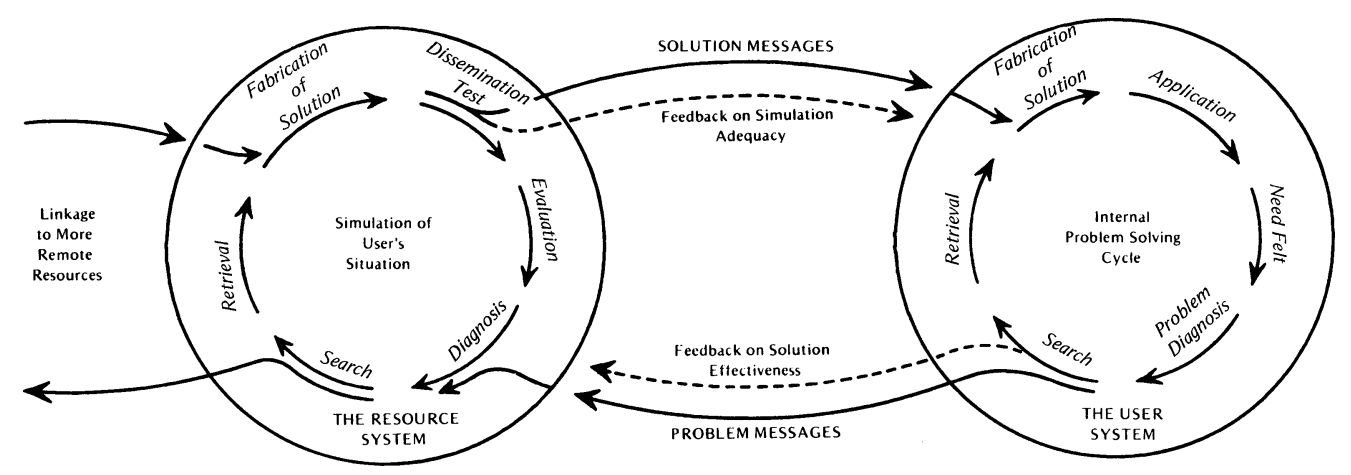

Figure 3 The Linkage Process (Havelock 1969: 11-16).

Such an approach to innovation implementation can therefore be seen as an attempt to combine the use of features associated with approach $\mathrm{C}$ with those of A, B and D. Although some indicative examples of its use in ELE innovation projects have been provided in Table 1 above, perhaps the best example of its application in ELE is to be found in the coursebook development cycle of major international publishers. As Donovan (1998) explains, such publishers are constantly engaged in gathering 'market' information from users of their own and others' products about aspects such as their effectiveness, potential for improvement, and so on, as well as keeping a 'weather eye' on trends in applied linguistics. This information is collated and fed back to editors, who then, in collaboration with authors, attempt to revise existing or create new teaching materials which take the users' feedback into account. The resulting drafts are then piloted and the feedback emerging from this process is relayed back to the publisher, and, as necessary, a further cycle of adjustment and additional trialling is undertaken. The overall success of this approach to innovation implementation can be gauged by the high level of market demand for coursebooks which have been developed in this manner. On the other hand, because of the anti-coursebook stance which prevails in much of the professional discourse (see e.g. Kumaravadivelu 2006), this important feature of the ELE innovation management landscape does not receive the attention it deserves, as indeed appears to be the case with respect to commercial innovation processes in ELE in general.

\subsection{Innovation roles}

In addition to the type of approach chosen, a further important innovation implementation variable concerns the nature and configuration of the various roles played by those involved in the process. 
The earliest conceptualisation of this kind in the ELE literature occurs in Kennedy (1988: 334-336) (though cf. White 1988: 118-119), where the system in Lambright \& Flynn (1980) for distinguishing innovation situation roles (one originating from the area of town-planning) is described and discussed. As Kennedy explains (p. 334), Lambright \& Flynn's classification comprises the following categories:

ADOPTERS: those who sanction the innovation (e.g. government officials);

IMPLEMENTERS: those directly responsible for putting the innovation into practice (e.g. teachers);

CLIENTS: those who are intended to be the primary beneficiaries of the innovation (e.g. students);

SUPPLIERS: those responsible for providing the resources needed for the innovation (e.g. materials writers);

ENTREPRENEURS: those with overall responsibility for managing the implementation of the innovation (e.g. 'change agents');

RESISTERS: those in opposition to the innovation.

Kennedy points out that this framework can be criticised for obscuring the way that roles can overlap (e.g. Implementers and others can also be seen as playing an Adopter role), as well as on the grounds that the Resisters category assumes a win-lose rather than win-win innovation model (pp. 334-335). The second of these criticisms can be seen as particularly pertinent with regard to the manner in which innovation in much of applied linguistics operates, in the sense that the overall strategy frequently appears to be based on a one-sided polarisation of academic vs. practitioner views, resulting in outcomes in which the perspective of the former dominates - in theoretical terms, at any rate - at the expense of the latter (see e.g. Waters 2009a, b; cf. Widdowson 1992). This is in contrast to the strategy put forward in Fullan 1998, one of attempting to accommodate resistance as a first principle of effective innovation management (see also section 3.3 below).

However, as Kennedy goes on to say, a categorisation of innovation project roles such as that of Lambright \& Flynn is potentially also very helpful in terms of aiding analysis of how relations and communication between the various parties involved in the innovation implementation process might be optimally configured (pp. 335-336). Thus, he argues that:

If, for example, adopters exercise a high degree of control over suppliers and implementers (often the case in centralized educational systems), the latter's freedom to adapt plans and to devise materials appropriate to their circumstances may be severely curtailed. This top-down planning approach means that feedback from clients, if collected at all, is rarely incorporated into revision of materials, and that feedback from implementers is seldom asked for and is not likely to reach upwards to the adopters. (Kennedy 1988: 335)

Lambright \& Flynn's categories can also be used to identify examples in the ELE literature of the opposite problem, where role relationships do not appear to have been configured closely enough, and where an excessive degree of responsibility was devolved by adopters to implementers, as in cases such as those described in Richards \& Pennington (1998), Carless (1999) and Waters \& Vilches (2008). Also, Wedell (2003: 452-453) (cf. Wedell 2009: 47-53 and section 3), on the basis of an extensive review of the problems caused by inappropriate configuration and realisation of roles in ELE innovation projects, provides 
an overall framework for properly linking together and accounting adequately for each of them at all of the main stages in the innovation implementation process (cf. section 2.3 above).

A further well-established conceptualisation of innovation roles, Rogers' (1983, 2003) ADOPTER CATEGORIES (see Figure 4), occurs in several parts of the ELE literature (see e.g. White 1988: 139-140; Markee 1997: 57-58). Briefly, Rogers argues that innovation 'adopters' (this time in the more generic, everyday sense of the term, rather than in Lambright \& Flynn's usage) can be seen as comprising five major categories, each of which is characterised by an overall psychological disposition towards innovation, as follows:

- InNOvATORs: 'Venturesome' (i.e., those who are characteristically pro-innovation in their orientation)

- EARly Adopters: 'Respect' (i.e., those whose are regarded by others as being sound judges of the value of potential innovations)

- EARly Majority: 'Deliberateness' (i.e., those who have a tendency to adopt a 'wait and see' approach to innovation adoption)

- Late Majority: 'Scepticism' (i.e., those who tend to adopt a critical attitude to the value of potential innovations)

- Laggards: 'Tradition' (i.e., those who have a preference for the status (ante) quo)

(Rogers 2003: 282-285)

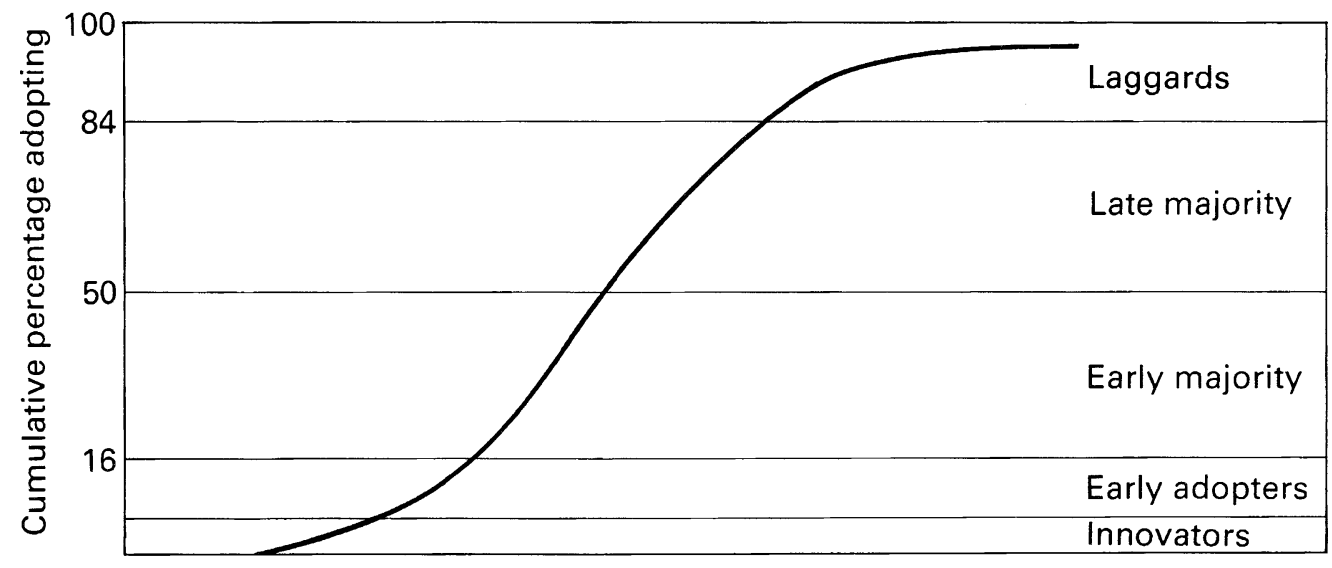

Time

Figure 4 The Innovation Adoption Curve (from White 1988: 139, based on Huberman 1973).

During the adoption process, those at the beginning of this list typically adopt sooner than those at the end, and, because of the way attitudes vary from one part of the adopter population to another, the adoption curve therefore takes a 'lazy S' form (Rogers 2003: 23), as shown. The most significant group in this process are the 'early adopters', since 'innovators' tended to be viewed with suspicion by the other categories, whereas a favourable attitude towards an innovation by the early adopters tends to be viewed positively by the 'early majority', their take-up having a consequent, similar, knock-on effect on the 'late majority' category, and so on. Rogers also indicates that, for innovation adoption 'take-off', it 
is necessary for a minimum CRITICAL MASS of adopters to exist, i.e., between $10 \%$ and $20 \%$ of the overall population (p. 12).

In terms of ELE innovation implementation management, the main implications of this categorisation have been seen to include the following. First, because of the S-shaped pattern it tends to follow, adoption of an innovation is unlikely to be rapid in the early stages, and therefore innovation management time-scales and expectations need to be adjusted accordingly (Markee 1997: 58). Second, especially in the early stages, the most crucial social group for the innovation manager to attempt to 'recruit' are the potential 'early adopters' (officials, teachers and others who act as opinion-shapers), because of their influence on other adopters (see e.g. Kennedy 1987; Markee 1997; Wedell 2003; Waters 2006; and section 4 below). Third, since it is essential that a 'critical mass' of potential adopters is recruited as soon as possible, this argues (inter alia) for the use of 'whole-school' and group-oriented teacher development strategies (see e.g. Hutchinson 1991, Goh 1999), rather than the more 'individualistic' approach typical of much ELT innovation work (such as 'counterpart training' via attending an overseas MA programme - cf. Richards \& Pennington 1998; see also section 3.3 below).

A further important body of work on the topic of roles in innovation implementation is contained in collections of papers concerned with ELE development aid projects, such as Crooks \& Crewes (1995) and Kenny \& Savage (1997). In the former, McGovern (1995) argues that it is important to empower 'insiders' as early as possible in the innovation development process, and that a primary means of doing so is to involve them in carrying out the project BASELINE STUDY (see section 3.4 below; cf. Wedell 2009). In a related vein, Martin \& Balabanis (1995) discuss the innovation project 'working party' concept (illustrated with reference to development of an Egyptian residential teacher training centre), i.e., a small management/development committee of insiders and 'outsiders' who engage in detailed joint decision-making, a system which, the authors argue, provides an effective way of getting round the lack of consultation and involvement of team members that so often typifies initial innovation implementation. Weir (1995), in the context of innovation project evaluation, sees outsider-based project 'accountability' evaluation and insider 'developmental' evaluation as not incompatible: experience gained in carrying out a baseline study in Nepal indicates that outsider objectivity and insider understanding can be complementary, and that it is more efficient to have insiders do data-gathering (see also Bray \& Luxon 1999). Smith (1995) argues that innovation project local COUNTERPARTS usually need more than expertise in subject and project management to be empowered in anything like the same way that foreign change agents usually are; typical obstacles to this are cultural, political, linguistic and economic; various possible solutions to the problem are also discussed, mainly based on adopting a proactive stance towards it (pp. 72-73). Similarly, Hlew (1995) stresses the importance of seeing counterparting as a form of cooperation and collaboration, and that counterpart trainers should have the right interpersonal skills for developing such relationships.

In the Kenny \& Savage (1997) volume, Smith (1997) discusses the way in which DONORS and RECIPIENTS in innovation projects typically have different priorities (cf. Medgyes 1994). Thus, for donors, these are likely to be, for example, achievement of project objectives, value for money and overall impact, whereas for recipients, they will usually centre around matters such as day-to-day problem-solving, minimising disruption and expense, and impact 
at the personal level. How these features played out and were dealt with in the context of a Cambodian-British Centre project is also described. In Murni \& Spencer (1997), a useful table for analysing the typical differences between counterpart and CONSULTANT ('change agent') role expectations is provided (see also Hollingworth \& Spencer 1997 below). Another useful table is provided in Hall (1997), concerning project roles in relation to project stages. A genuinely collaborative approach among stakeholders in terms of flexibility of goals, professional support and evaluation is seen as crucial for innovation project success.

The primary overall contribution made by this part of the literature, then, is the way that it highlights the need for the foreign aid project as a vehicle for innovation to be managed in such a way that its inevitable 'outsiderness' is taken into account and compensated for as far as possible, particularly by the establishment of close and genuinely collaborative working relations between insiders and change agents. However, despite the examples of good practice just described, it seems clear that, unfortunately, the norm in much ELE innovation work is for the differing perspectives of innovators and end users in general to be insufficiently reconciled, as many of the case studies investigating lack of success in ELE innovation mentioned above (see also Hayes 2000: 135-136).

Finally, we consider the literature on the ELE change agent - the person responsible for the overall planning and day-to-day execution of the innovation implementation process (cf. Lamie 2005: 19-20). McGovern (1995: 14), on the basis of an analysis of an innovation project diary kept by two ELE change agents in the context of a major national basic education project in Nicaragua, concludes that, in addition to expertise in ELE and teacher training, 'certain types of knowledge and skills which are not typically taught on Masters degrees in Applied Linguistics' were also needed for the change agent role. He sees these as including inter-personal skills, an ability to handle project politics, negotiations skills, team-building skills, and an understanding of budgeting and marketing.

Hollingworth \& Spencer (1997: 7) argue that 'training consultants [i.e., inter alia, change agents] on educational development projects usually seem to be appointed for their academic qualifications and teaching experience without regard to demonstrable training or skill in managing change' [my interpolation]. Furthermore, they take the view that 'the contribution consultants make will be determined by their skills as change-agents' (ibid) and that they will usually need to attempt to effect change at the systemic rather than just individual level, in the larger rather than solely institutional environment, and in a context where the capacity to cope with the change may be lacking. On the basis of their analysis of a number of change situations, particularly in terms of power relations (including some telling examples culled from the film Sister Act!), the authors go on to conclude that

[change agents] must be able to devise strategies. For this they need to understand persistence and change in human systems. They need to know how to test for commitment and change potential, how to build a power base, how to enlist cooperation, and how to overcome resistance. They need an overall conceptual scheme of things in which all of the relevant knowledge can cohere, a framework which guides strategic planning. (Hollingworth \& Spencer 1997: 79)

They then discuss one such strategic planning framework, based on Mason \& Mitroff (1984) and Capelle (1979), concerned with 'how strategic power is obtained in human systems' (ibid), and end by illustrating their ideas by reference to two innovation case studies (pp. 82ff.). 
Kennedy (1997), in the context of discussing the need for teacher trainers to become change agents, describes some of the elements of the model of change agent expertise in Buchanan \& Boddy (1992) (developed originally out of the authors' research into the management of industrial and commercial information technology innovation projects), and which he argues can be seen as also forming parts of the expertise of the ELE change agent (see also Bray \& Luxon 1999). The elements in question comprise skill in the handling of three main "macro" areas'. The first of these is Content, i.e., 'expertise in the "subject" or area of the change' (p. 129); the second is Control, which 'centres round the techniques of management that a change agent requires ... such as budgeting, reporting, planning' (p. 130); the third area is Process, i.e., 'the sorts of interpersonal and political skills required to manage change' (ibid). To these three he adds a fourth area of his own, which is seen to cut across the first two, namely Technology, i.e., expertise 'related to technology management, particularly information technology' (p. 131). Also mentioned are some of the 'subskills or competencies' (p. 132) which Buchanan \& Boddy (1992) see as underlying the 'macro skills', such as 'skills in problem solving; ability to question and be critical; ability to see patterns; high cognitive orientation; analytical skills ... creativity' (pp. 132-133). The remainder of Kennedy's paper goes on to illustrate a method of developing such subskills in relation to the Content area, via an awareness-raising approach to developing language knowledge.

To sum up. The ELE literature concerned with this area highlights the multiplicity of roles involved, as well as the complexity of configuring and executing them as effectively as possible (cf. White 1988: 118-119). In particular, it is clear that the knowledge and skills required for the crucial role of the change agent extend well beyond a knowledge of the ELE innovation, the area of expertise which, however, appears to predominate among those involved in ELE innovation activity in this capacity. In overall terms, thus, the items in this section help to throw light on the problematic nature of roles in ELE innovation implementation, as well as how some of the potential pitfalls involved might be avoided.

\subsection{Psychological processes in innovation implementation}

Another important section of this part of the literature is concerned with the psychological processes experienced by innovation implementers, i.e., those directly involved in attempting to put innovations into practice, chiefly teachers.

An overall reference point for conceptualisation in this area is provided in Malderez \& Bodóczky (1999: 15), where the psychology of the teacher is pictured as akin to the structure of an iceberg and the way it interacts with its environment (an outline version of their diagram is provided in Figure 5). Professional behaviours make up its visible tip, but these are seen to interact with portions of the psyche which lie below the 'surface' (indicated by the dotted line), and which are viewed as comprising conceptualisations of (i) at the 'ideas' level, the teacher's immediate teaching-learning situation and, more broadly, of the nature of language learning and education in general, as well as of (ii) at the 'attitudes' level, everyday perceptions and beliefs about the world at large (the 'attitudes' level). Interaction is also seen to take place between all these elements and the surrounding educational and socio-cultural contexts. 


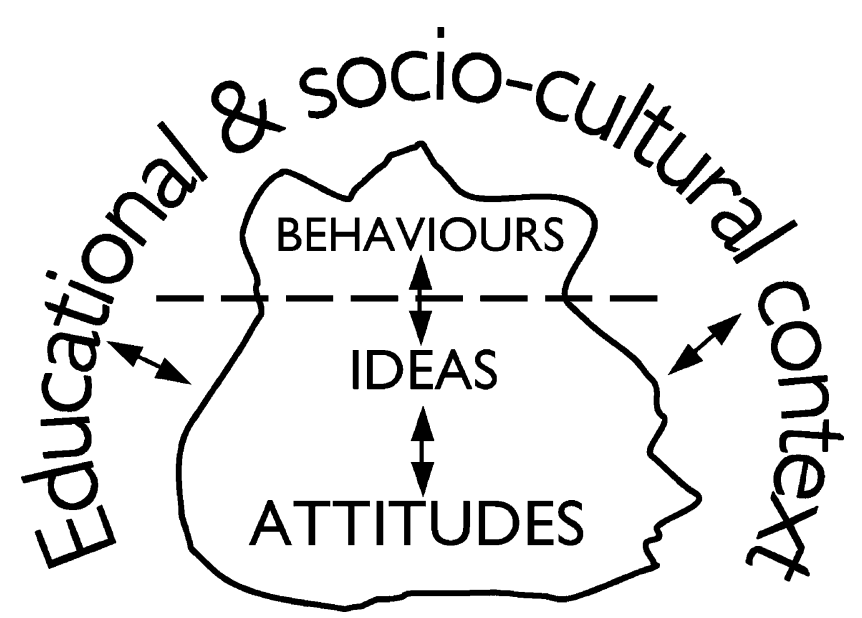

Figure 5 The Teacher Iceberg (Waters 2005: 217, based on Malderez \& Bodóczky 1999: 15).

Such a conceptualisation of teacher psychology resonates with the characterisation in Fullan \& Stiegelbauer (1991), as discussed in Karavas-Doukas (1998: 28ff.), of significant educational innovation being SECOND-ORDER in nature. Change of this kind involves alteration of 'the fundamental ways in which organizations are put together, including new goals, structures, and roles' (Fullan \& Stiegelbauer 1991: 29), and is 'multidimensional', i.e., encompassing '(1) the possible use of new or revised materials..., (2) the possible use of new teaching approaches..., and (3) the possible alteration of beliefs (for example, pedagogical assumptions and theories underlying particular new policies or programs)' (Fullan \& Stiegelbauer 1991: 39). In other words, the accommodation of change by teachers needs to be seen as involving all the levels of the 'iceberg', as well as their dynamic interplay (cf. Kelly 1980 in section 2.2 above, whose three criteria for innovation adoption by teachers feasibility, relevance and acceptability - can also be seen as congruent with the three main levels of the iceberg (Waters 2005: 218), and see also Hutchinson 1991 below, regarding the role of 'key meanings' in this conceptualisation).

The implications for innovation implementation of such a model of the teacher are further reflected in various ways in the following parts of the literature. First, drawing on Ajzen's (1988) THEORY OF Planned Behaviour (TPB), C. Kennedy \& J. Kennedy (1996) (cf. D. Kennedy 1999; Keranen 2008) show how, although teachers' attitudes towards a teaching innovation may be positive, their willingness to actually implement it may be another matter. This can occur because, as the TPB indicates, intentions are a product not only of the relative strength of the beliefs which shape attitudes, but also of those which formulate conceptualisations of 'subjective norms' and 'behavioural control'. The former refers to the extent to which the behaviour in question is seen as likely to meet with the approval of 'gate-keepers' and others in a teacher's milieu; the latter comprises perceptions of one's ability to carry out the behaviour in terms of personal ability and the constraints of the environment in which it will occur. As C. Kennedy \& J. Kennedy (1996: 352-353) explain, because of such factors, a teacher may, for 
example, espouse favourable attitudes towards exercising greater tolerance of learner error, but fail to translate such views into practice because of a self-perceived lack of alternative error treatment strategies, and/or out of a concern that institutional authorities, parents and others may disapprove. The understanding of the complexities of implementation psychology which the TPB perspective provides thus helps to throw light on why innovations which do not appear to show awareness of it typically experience difficulties (see e.g. Young \& Lee 1984; Henrichsen 1989; Lamb 1995; Karavas-Doukas 1998; Carless 2002; Waters \& Vilches 2008).

Beretta (1992) (see also Markee 1992: 231) discusses the use of two more conceptual frameworks which throw further light on the psychological nuances of innovation implementation by teachers. The two systems in question - LEVELS OF UsE and STAGeS OF CONCERN (Hall \& Hord 2001) - were used by Beretta to analyse aspects of the implementation of the well-known Bangalore Project (Prabhu 1987). Briefly, the former distinguishes between several different levels of innovation implementation behaviour that a teacher may exhibit at any given point in the implementation process, varying from, for example, Mechanical Use (a relatively unreflective, 'attempting to cope' use of the innovation), to Renewal (autonomous redevelopment of the innovation) (Hall \& Hord 2001: 82). In the Bangalore situation, this framework indicated more developed levels of use among 'non-regular' teachers (i.e., British Council staff, teacher trainers and others teaching in the project schools on an occasional basis) than among 'regular' ones (those teaching in the project schools on a full-time basis) (Beretta 1992: 253-254).

The companion Stages of Concern (SoG) model provides a method for determining the kind of affective reaction that teachers may have towards an innovation at any given stage in the implementation process, ranging from, for example, early Management concerns (where the preoccupation is with administrative and logistical aspects of using the innovation) to later Refocusing ones (in which attention is concentrated on the potential of the innovation as a springboard for further development) (Hall \& Hord 2001: 63). In the context of the Bangalore study, non-regular teachers consistently had greater early concerns than those of the regular ones (pp. 254-255) (cf. Lee 2007, in connection with an analysis of the implementation of the Malaysian SMART School Project).

Use of these two frameworks to analyse behavioural and affective aspects of innovation implementation by teachers therefore helps to show that, in these ways as well, the implementation process as experienced by front-line implementers is typically not a monolithic event, but, rather, can be variable in nature and hedged about with complex psychological effects. Clearly, such a perspective once again helps to throw further light on the causes of lack of success in ELE innovations, by highlighting the need for, for example, greater and more differentiated levels of support for teachers in their implementation efforts (cf. Wedell 2003, 2009).

The discussion of ideas in Blackler \& Shimmin (1984) and Marris (1974) (cf. Fullan 2001b: 30-32) in Hutchinson (1991), about how individuals and groups cope with change, provides further insight into the psychology of teacher responses to the innovation implementation process. Thus, as Hutchinson explains, significant change tends to be experienced as a potential threat to what Blackler \& Shimmin call an individual's KEY MEANINGS, i.e., 'schemata' developed on the basis of various everyday life experiences, and which provide the 
predictability, security and self-worth necessary for coping successfully with daily existence (Hutchinson 1991: 20). Individuals' membership of social groupings are also important in the development of key meanings, as is the way that, in return for the rewards groups provide, individuals will tend to conform to their norms.

Because change disturbs the way key meanings are configured, the characteristic response is one of resistance, what Marris (1974: 22) calls the CONSERVATIVE IMPULSE, i.e., a desire to preserve key meanings in their existing form. Hutchinson (1991: 21) therefore argues that, in the management of innovation, '[p] eople should be encouraged to express their resistance. So long as resistance remains hidden, it remains a problem and a potential threat to the success of the change' (cf. Fullan 1998: 256). This is in contradistinction to much ELE innovation implementation practice, where resistance is often seen in only a negative light, or rationalised as due to the failings of teachers (see e.g. Kouraogo 1987; Waters 2009b; Wedell 2009: section 2, passim), rather than its causes and potential remedies taken properly into account. Hutchinson also argues that ' $[\mathrm{t}]$ he power of groups to affect individual behaviour is generally ignored in ELT teacher training, where teachers are by and large trained or retrained as individuals', and therefore that ' $[\mathrm{t}]$ he logic of the ideas on group norms argues in favour of educating teachers in their normal work groups, i.e. their school, faculty or department' (p. 20) (cf. Fullan 1998: 257-258).

An additional and closely-related innovation implementation concept is that of the TRANSITION CURVE, a representation of which is provided in Figure 6 (Waters 2005: 221; see also e.g. Scott \& Jaffe 1990; Bridges \& Mitchell 2000).

From this perspective, because of the restructuring of key meanings involved, the competence of individuals faced with significant change, after some initial fluctuation, typically suffers a steep decline, an experience akin to what Fullan (2001a: 40-41) calls the IMPLEMENTATION DIP. The key to moving beyond this stage is the 'acceptance' phase, in which the individual begins to be reconciled to the inevitability of the change. This is followed by a series of steps resulting in rising levels of ability to cope with the change. Typically, these begin with a 'testing' (or 'recipe book') phase - one associated with a desire for structured guidance and other certainties which can help to define as clearly as possible what the new knowledge and skills are that are needed for successfully handling the change - and ends with the 'integration' part of the cycle, when the change has been successfully incorporated into a new, restructured set of key meanings.

Waters (2005: 222-223) discusses a number of the implications for the management of the innovation implementation process that arise from the nature of the Transition Curve, such as the need to emphasise the continuity between the innovation and existing key meanings. Also, many of the points made in Hutchinson \& Hutchinson (1996), about the value of the textbook as an 'agent of change' in ELE innovation projects, are of particular relevance to the crucial testing/recipe book stage of the process, since, by the provision of fully-developed teaching materials, teachers are more likely to be equipped with the necessary level of detailed and explicit guidance needed to support their efforts to implement new teaching ideas. However, the potential for textbooks to re-skill teachers in this way is in contradistinction to the antitextbook, 'de-skilling' stance which prevails in much of applied linguistics (see e.g. Allwright 1981; Kumaravadivelu 2006), notwithstanding reports on the negative consequences of the lack of provision of this resource in ELE innovation projects, such as Karavas-Doukas (1998), 


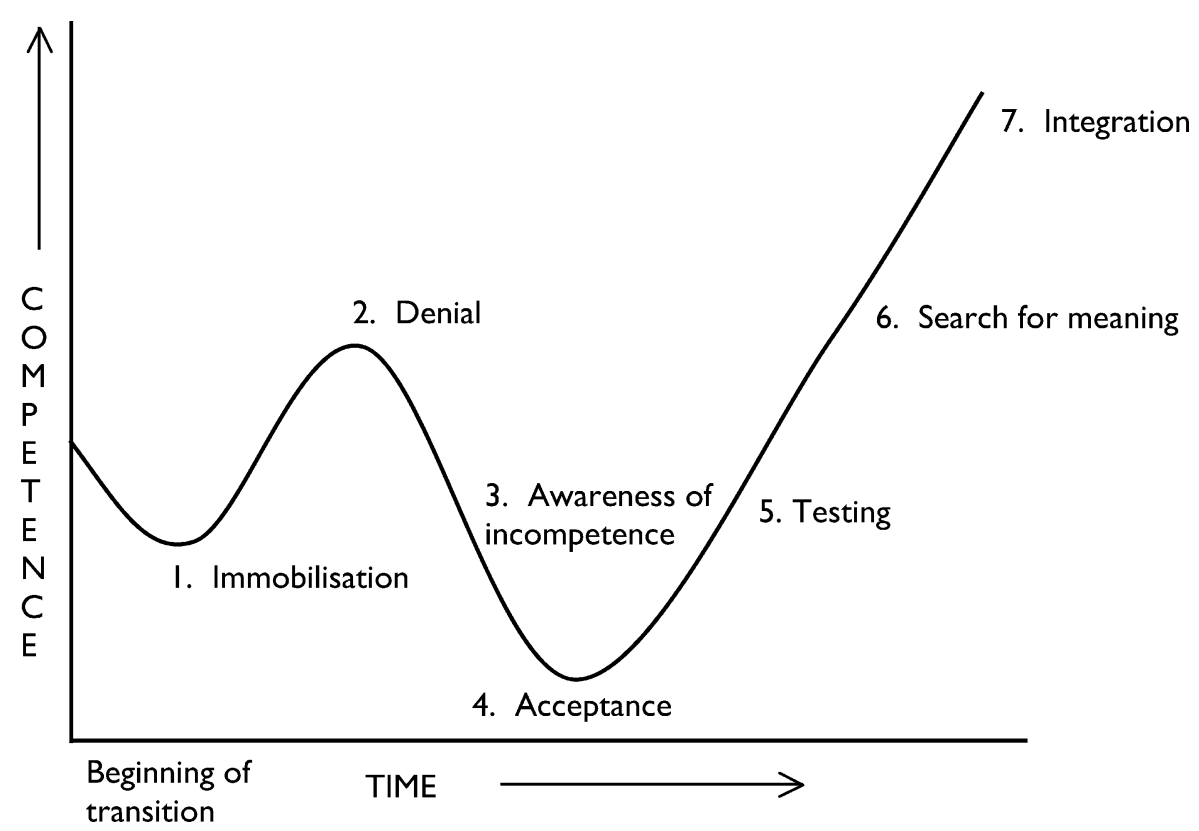

Figure 6 The Transition Curve (from Waters 2005: 221).

Carless (1999), Waters \& Vilches (2008); cf. Fullan (2001b: 79). White (1988: 114), on the other hand, warns against the possibility of 'teacher-proof' materials precluding the level of 're-invention' innovations usually require; however, data in Hutchinson \& Hutchinson (1996: 319 ) indicate that, in practice, 'teachers and learners do not follow the textbook script'.

\subsection{Evaluation}

A further important part of the ELE innovation implementation literature is concerned with evaluation, defined in Rea-Dickins \& Germaine (1998b: 12) as "the "POTENTIAL" to make judgements and recommend, to evaluate effectiveness and efficiency and to contribute to curriculum improvement and development' [original emphasis]. In keeping with this dual characterisation of the concept, we shall look first at literature concerned with the 'judgemental' role of evaluation in ELE innovation projects, and then, secondly, its 'developmental' role (p. 13).

In terms of the former, Kennedy (1988: 341-342) includes a set of 'questions for the evaluation of change management in ELT projects', which can be seen as concerned with broad themes of (i) suitability to context, (ii) communication and commitment, and (iii) the weighing up of likely benefits against existing dissatisfactions. Alderson (1992: 281-282) provides a list of areas that can be used as the basis of a retrospective (summative) innovation project evaluation, and Weir \& Roberts (1994: 17-20), drawing on Sanders (1992: 5-6), present a comprehensive listing of possible areas for innovation project evaluation, as well as a useful discussion of the attendant issues and problems associated with selecting and 
examining them. ${ }^{3}$ Celani (1994: 43-47) includes a set of criteria for assessing wider and longer-term impact of innovation projects of a kind that might not have been anticipated at the outset (e.g. effects on the teaching of other subjects, not just English).

A further major trend in the evolution of criteria for ELE innovation evaluation occurred as a result of the introduction of 'projectisation' in development aid projects of the 1980s, especially in the context of those sponsored by the UK Overseas Development Agency (ODA). ${ }^{4}$ This was because of the use of LOGFRAMES in such projects (see e.g. Alderson 1992: 291-292, 300-302; Weir \& Roberts 1994: 13; Markee 1997: 80-86), requiring the use of clearer and more precise evaluation criteria for guiding project implementation and assessing overall impact, through, in particular, the need to include concrete 'Indicators of achievement' and measurable 'Means of verification' for objectives and outputs.

However, McGovern (1995: 3-15), echoing concerns expressed in a number of other sources (e.g. Alderson \& Beretta 1992; Weir \& Roberts 1994; cf. Woodhall 1994), points out that 'the project approach' originated as a device for control of expenditure in infrastructure projects, rather than as a means of diffusing educational innovations. He argues that the kind of evaluation criteria it fosters can therefore be criticised for being too short-term and productoriented, and that project goals should be less concerned with products and structures and more with impact on people, with the full range of potential stakeholders being taken into account.

More recently, a further set of innovation evaluation criteria has been developed in the form of the INTERPERSONAL MODEL included in Lamie (2004) and (2005), one developed as a result of the research described in the former and by building on ideas in, inter alia, Ajzen (1988), Kennedy (1988), Fullan \& Stiegelbauer (1991) and D. Kennedy (1999). Her framework comprises a number of main potential 'impact areas' (i.e., 'various internal and external issues' (Lamie 2004: 124)) which can affect the likelihood of meaningful innovation adoption on the part of the intended end user. The 'impact areas' include 'personal attributes' (attitudes and confidence), 'practical constraints' (textbooks, class size, etc.), 'awareness' (knowledge/understanding related to the innovation), and 'training' (Lamie 2005: 66-80). The main value of this evaluation system would seem to be the way that, in a relatively concise manner, it centres on three interlocking concerns, namely (i) the personal qualities of the potential adopters, (ii) the nature of the innovation context, and (iii) the innovation content and implementation strategies (cf. Lamie 2005: 56), thus creating a convenient synthesis of earlier work.

The second main aspect of evaluation in ELE innovation implementation evinced by the literature and referred to earlier is its 'development' function. This, the importance of integrating evaluation activity as fully as possible into all aspects of innovation project management, is, like the 'judgemental' aspect, also mentioned in Kennedy (1988). Thus, as he points out, evaluation questions of the kind included in his paper and reproduced above might be asked 'in order to evaluate a project plan prospectively before implementation' and, 'since evaluation should be built in throughout the planning process, such questions

\footnotetext{
${ }^{3}$ Information about, and discussion of, techniques and tools for carrying out innovation project evaluations can be found in, for example, White (1988: 148-155), Alderson (1992: 274-304) and Weir \& Roberts (1994: part III and appendices).

${ }^{4}$ Now the Department for International Development (DfID).
} 
can also be asked during the project to monitor progress, adjust plans, and provide warning signals of problems ahead (formative evaluation)' (p. 341). In other words, it is seen as desirable for evaluation to be used to guide innovation project management during the initiation and implementation stages as well, that is, to also have a 'formative', not just a summative role.

A similar concept is also outlined in White (1988: 148), and subsequently reinforced in Rea-Dickins \& Germaine (1998b). In the latter, on the basis of a review of a number of recent evaluation studies, it is concluded that 'we have identified a change in evaluation practice in language education ... in the way in which evaluation is currently defined, with a paradigm shift evidenced' (p. 11). Part of this process has involved a greater focus on the 'UTILISATION function of evaluation in professional practice... Evaluation is intended to have immediate utility for policy shaping and is expected to be influential in short-term decision making' (ibid; original emphasis). Detailed illustrations of the use and value of evaluation of this kind in ELE innovation projects can be found in a number of the papers included in Rea-Dickins \& Germaine (1998a), such as Mackay et al. (1998), in papers in Alderson \& Beretta (1992) such as Coleman (1992), and in, for example, Weir \& Roberts (1994), Williams \& Burden (1994) and Markee (1997: 130-134).

Another main theme running through this part of the literature is a focus on the potential benefits for innovation project development of maximising 'stakeholder involvement' in evaluation activity. Thus, it is argued in, for example, Weir \& Roberts (1994), McGovern (1995), Weir (1995), Bray \& Luxon (1999) (cf. Wedell 2009), that a number of potential benefits in terms of innovation project management can accrue from the involvement of insiders in the form of project evaluation activity known as the BASELINE STUDY. The purpose of such a study is to gather information at the 'appraisal' and/or implementation stages of an innovation project in order, for example, to determine its feasibility, to provide a basis for later evaluation of project impact, and to identify appropriate 'zones of innovation' (Stoller 1994 - see section 2.2 above) and the means of achieving their realisation. With reference to a variety of innovation projects in different parts of the world (Ukraine, Cambodia and Nicaragua) and using the framework of change agent skills in Buchanan \& Boddy (1992: 28) (see section 3.2 above), Bray \& Luxon (1999: 35-38) show how the execution of a baseline study can lend itself particularly well, through the involvement of project insiders, to their acquisition of a wide range of transferable innovation project management skills, as well as providing the basis for subsequent project accountability and development (though see Weir (1995: 42) regarding the importance for success in this respect of a number of preconditions).

In overall terms, thus, the literature on evaluation in ELE innovation projects evinces, on the one hand, a gradual development and refinement in frameworks for attempting to establish the overall degree of success of innovations, and also an increasing interest in the use of formative evaluation information to monitor and fine-tune (inter alia) the implementation process, as well as achieve greater involvement and empowerment of project implementers. However, at the same time, it is clear that a number of recent large-scale ELE innovation projects have lacked well-developed implementation monitoring, feedback and adjustment systems of the kind needed, such as those described in Karavas-Doukas (1998), Goh (1999), Sakui (2004), Lee (2007), Waters \& Vilches (2008) and Prapaisit de Segovia \& Hardison (2009). It can also be argued that, at a superordinate level, much of applied linguistics - the 
major engine of innovation in ELE - by virtue of the frequent adoption of a 'top-down', 'linguistics applied' stance (Widdowson 1992, 2000) and because of the absence of any major meaningful feedback loop from the practitioner level, lacks the necessary means for properly evaluating both the overall and ongoing impact of many of the ELE innovations it proposes. It is thereby locked into a cycle that prevents the development of sufficient professional self-reflection (cf. Waters 2009b).

\section{Innovation institutionalization}

We come finally to the third of the main stages in the model in Figure 1 above, what Fullan (2001b: 51) terms InstiTUTIONALIZATION (often referred to in ELE circles, as already explained, as a concern for creating innovation 'sustainability'), i.e., attempting to ensure that innovations remain in long-term use.

Unfortunately, it has to be said at the outset that even a brief glance at the literature makes it clear that ELE innovation projects have often lacked a number of the elements needed to facilitate institutionalization. Typical examples of the problem include the cases described in, for example, Henrichsen (1989), Tomlinson (1990), Markee (1997: 9-15) and Richards \& Pennington (1998). For example, a major motivation behind the construction of the Hybrid Model (Henrichsen 1989; see section 2.3 above) was to attempt to account, as thoroughly as possible, for the distinguishing features of an innovation proposal, on the one hand, and, on the other, for the primary features of the host environment likely to affect its potential for longterm adoption. As Henrichsen (ibid) graphically shows, it was the almost complete failure to identify and take into account such variables which led to the comprehensive lack of success of the ELEG effort. Thus, by implication, one of the conditions necessary for sustainability of ELE innovations is that they are designed and implemented in such a way that there is as thorough an understanding as possible of the factors likely to affect long-term take-up.

One element of this kind appears to be the building-in of an overall strategy for fostering innovation sustainability right from the start, instead of attempting to address the issue only when the initial project implementation phase is complete. Some of the means of adopting the former approach have already been mentioned in the previous section, in connection with the involvement of project insiders, from the earliest point, in project evaluation and development (McGovern 1995; Bray \& Luxon 1999; for an equivalent approach, involving later stages of project implementation, see Hall 1997 and Jackson, Piper \& Yildiz 1997).

In addition, in discussing the Indonesian LAN English Language Training Project, Marpaung \& Kirk (1997: 247) present a project planning and development framework, based on Crocker (1987), for taking sustainability into account from the outset. In this approach, a distinction is made between innovation project 'order of importance', on the one hand, i.e.

- institutional development

- staff development

- resource development

- program development 
and a reverse 'order of implementation', on the other, i.e.

- program development

- resource development

- staff development

- institutional development

As the authors explain (p. 2), quoting Crocker (1987),

The importance of each component runs top-down from the list, since those above are, in project terms, invariably necessary (but not sufficient) pre-requisites to achieving objectives in the area immediately beneath. This is easy to forget, given that the order of implementation created by the operational priorities of the project invariable runs from the bottom upwards.

And they later say (p. 248):

In other words, ultimately a project will be sustainable only if it becomes a formal part of the institution in which it is based, and institutional development efforts must be made to ensure that this takes place... Program development is probably the category on which the adviser will spend most time. But he or she must always bear in mind that the most important aspect is institutional development which enables the long-term sustainability of the project's activities.

This approach, thus, depends on distinguishing between what is 'urgent' and what is 'important' in innovation development. Keeping such an overall perspective in mind from the start can be regarded as crucial to achieving the level of institutionalization needed for sustainability.

A further, related aspect of the sustainability issue in ELE innovation concerns the distinction made in Markee (1997: 172ff.) between PRIMARY and SECONDARY innovations, the latter being the additional resources, such as teacher development programmes, which are essential for ensuring the institutionalization of primary innovations (such as a new teaching approach). An evaluation of Markee's CATI project indicated that its teaching assistants did not understand the relationship between their involvement in materials development and their own professional development, and their levels of project 'ownership' were therefore lower than desirable (Markee 1997: 164). As a consequence, a number of preliminary steps were taken, involving sharing and detailed discussion of the evaluation information between Markee as project leader and the teaching assistants, resulting ultimately in the creation of a number of secondary innovations aimed at remedying the problems. For example, the position in the accompanying programme of academic studies of the course concerned with materials development meant that although the teaching assistants 'could DEVELOP materials, they had few opportunities to USE them' (p. 165; original emphasis). In order to solve this problem, a considerably expanded and re-sequenced materials design component was introduced.

It is therefore possible to see that a significant factor in the achievement of innovation project institutionalization is the adequate provision of 'secondary' innovations. As a corollary, it can be seen as particularly important, when introducing new teaching approaches or materials, for teachers to be provided with opportunities, to paraphrase Markee (1997: 165) above, 
to not only learn about them but to also be supported in actually USING them within the target teaching context (cf. Wedell 2009: 36-37). Although some exceptions can be found (e.g. Roberts 1998: 258-275; Tomlinson 1988; Goh 1999; Waters 2006), in general, the focus of teacher learning in ELE innovation projects, especially at the in-service level, has tended to be much more course- than school-based (Waters 2002). It is arguable that, as a result, the level of institutionalization of new teaching ideas in such projects, and thus their potential for sustainability, has frequently been less than needed. This is in contradistinction to the picture evinced by the non-ELE literature (see, for example, Fullan \& Stiegelbauer 1991; Adey 2004; cf. Waters 2002), which records a long-standing recognition of the need for educational innovation projects to complement course-based teacher learning with extensive school-based follow-up support, in order to create the levels of institutionalization needed for long-term 'ownership' (cf. Wedell 2003: 453).

Finally, there is also relatively little said in the ELE innovation literature (but see, in particular, Wedell 2003; Wedell 2009) about the importance for enhancing sustainability of recruiting the support of and nurturing close relations with 'gatekeeper' figures, such as leading local academics, teacher trainers, educational administrators, senior teachers, heads of department, principals, advisers and the like (cf. 'early adopters' in section 3.2 above). Such personnel, because they are involved in influencing the teaching ideas and/or management of the education and school systems, have the power to make or break the institutionalization of an innovation. In general, however, the tendency in a good deal of ELE 'stakeholder analysis' appears to have been to either ignore or attempt to by-pass such figures (see e.g. Henrichsen 1989; Tomlinson 1990; Markee 1997: 9-15; Richards \& Pennington 1998; Godfrey et al. 2008).

More positively, however, Kennedy (1987), in the context of describing the use of a mainly 'normative-re-educative' approach to bringing about change (Chin \& Benne 1970; see section 3.1 above) in a Tunisian university ESP unit, also discusses the importance of ensuring the support of the institutional 'powers that be' to the success of such projects, and distinguishes between the involvement of system or institutional managers and others in a 'power-coercive' vs. a 'supporting' role. The latter is seen as an essential part of establishing the legitimacy of the change agent to effect change (cf. Buchanan \& Boddy 1992: 88). Similarly, Waters \& Vilches (2001: 139-140) argue that provision needs to be made in any ELE innovation project for an 'ELT manager' orientation programme, aimed at encouraging integral involvement of such personnel in the project (though see Waters (2006: 47) concerning some of the problems and practicalities of designing an effective system of this kind).

Thus, in general, the ELE innovation literature shows that institutionalization is more likely to be achieved if (i) the innovation is designed and implemented in such a way that it is embedded in the interstices of the host habitus to the greatest possible extent; (ii) strategies for increasing the potential for sustainability are built in right from the outset, rather than only taking the form of post hoc bolt-on extras; (iii) a sufficiency of secondary innovations are provided, so that the kind of support needed to achieve the necessary level of in-depth understanding and ownership by implementers is created; and (iv) system managers are recruited to the cause of the innovation, so that the necessary support for sustainability at this level is also ensured. On the other hand, it is equally clear that, unfortunately, a number 
of these features have frequently been lacking in ELE innovation projects, resulting all too often in lack of long-term success.

\section{Conclusion}

What, then, can be concluded in overall terms about the current state of the art of managing innovation in ELE, and what priorities for further development can be discerned?

First of all, it is obvious that there is now a substantial body of literature on the subject, and, with several important book-length publications having appeared in recent years (Lamie 2005; Murray 2008b; Wedell 2009), it shows signs, if anything, of gathering further momentum. This has resulted in a reasonably comprehensive coverage of the field. However, at the same time, important lacunae also exist.

Thus, the literature embraces a very wide range of GEOGRAPHICAL SITUATIONS, but there are significant gaps in terms of areas such as Latin America, non-Anglophone parts of Europe, and, in recent years, the Middle East. Many types of INNOvATION CONTEXTs are covered, at all three main educational levels, both in terms of private- and public-sector settings, though the former is represented to a significantly lesser extent than the latter. In terms of TYPES OF INNOVATIONS, there are a large number of accounts of attempts to change aspects of teaching methodology and teaching materials, as well as of initiatives concerned with teacher training, but, on the other hand, innovations involving the use of information technology, institutional restructuring and changes in senior personnel in organisations are all under-represented. And, while coverage of INNOVATION DESIGN AND MANAGEMENT PROCESSES is reasonably wide and varied, some areas (such as 'levels of implementation' - see section 3.3 above) do not appear to have diffused as they might.

Also, despite some important exceptions, the vast majority of items in the ELE innovation literature are written by native speakers of English, draw on literature from the Englishspeaking world for much of their academic background, and tend to be associated with native speaker-led innovation experiences. It therefore seems inevitable that the overall picture in this respect is a culturally-biased one. Thus, after outlining the problem-solving, participative, interactive and 'learning by doing' innovation management approach used in the CATI project, one typical of what is advocated in much of the rest of the literature, Markee (1997: 175-176) points out that

such a model of curricular innovation is very much an artefact of the sociocultural context that gave birth to this view of how to manage change. It is therefore quite likely that other models and strategies of change may be culturally more appropriate in contexts of implementation that have more centralized traditions of how to manage change. This aspect of the educational change literature is very much underdeveloped, and further research is needed.

As this review has demonstrated, the situation described by Markee more than 10 years ago does not seem to have changed a great deal, though a number of important ELE innovation studies by writers with different sociocultural backgrounds from the one that Markee mentions have subsequently been published, such as Karavas-Doukas (1998), Li (1998), Goh (1999), 
Hu (2002), Sakui (2004), Lee (2007), Goh \& Tay (2008), and, slightly earlier, Shamim (1996). Clearly, it is important that this trend continues and expands, so that a less potentially ethnocentrically-biased picture of what is involved in effective ELE innovation management is built up.

This said, in the situations which they describe, many of the studies just mentioned both lament the absence and indicate the potential value of a model of change of the kind referred to by Markee. Also, it is clear that, despite the identification of the model with the Anglophone west, actual innovation practice in that part of the world is frequently a different matter, as indicated in much of Fullan (2001b). Indeed, in a survey of a large number of Australian innovation project teacher development programmes, Ingvarson, Meiers \& Beavis (2005: 17) conclude that

[t]he findings from this cross-program analysis reflect findings from other research on professional development and challenges that policy makers have faced for many years. These studies often find a considerable gap between the conditions that research indicates are optimal for professional learning and those that are provided.

Furthermore, in Lee (2007: 277-282), it is argued that the drawbacks identified in the operation of the Malaysian SMART School Project professional development system came not so much from the operation of an overall top-down innovation strategy, but, rather, from a failure to ensure that the more 'normative-re-educative' elements (see section 3.1 above) which it also included were made to work in the intended manner. Therefore, however paradoxically, here the solution to the problem is seen to lie in the direction of a more effective application of centralised leadership (cf. Goh 1999). The overall challenge, therefore, would seem to be one of how to create the potential for more effective innovation within systems which, in all parts of the world, tend currently to operate in ways which make this difficult to achieve.

A further important gap is the one that exists between the body of literature on innovation management concepts and practices that we do have, both within and outside ELE, on the one hand, and the continuing tendency in the literature on ELE innovation activity for much or all of this information to be ignored. Out of the 13 chapters in as recent a volume as Murray (2008b), and despite their other considerable merits, very few make any kind of reference to innovation management concepts of the kind which this review has focused on. This is of all the more concern, when, as Murray makes clear in her 'Introduction' (Murray 2008a), the intention has been to show how, on the one hand, certain approaches to the management of change result in 'predicted outcomes' being 'challenged, reshaped, or rejected', and, on the other hand, how others enable change to be 'co-constructed by teachers and change agents' (p. 1). Thus, although gaps exist in the ELE innovation management literature, as has been indicated, and which it is important to remedy, probably the most urgent need is for the overall approach to innovation of the ELE professional discourse to become much better acquainted with and responsive to the important guidance which, even its present form, it is capable of providing. One way this might occur would be if training programmes and textbooks about ELE were to more frequently include sections on 
innovation management theory, and its application, in the manner of, for example, White (1988).

This said, it is also important to be realistic about what can be achieved, and avoid succumbing to what, to paraphrase Rogers (1983), might be referred to as 'pro-innovation THEORY bias'. As Wedell (2009: 5) points out,

[ $\mathrm{t}$ ] he literature suggests that a virtually infinite set of interdependent variables may affect the extent to which, and speed with which a recognizable version of an educational change becomes visibly implemented in (the majority) of classrooms, or indeed whether there is any change at all.

There is therefore probably far more that is NOT known about effective innovation in ELE than is currently understood. However, as Wedell (2009) also says, 'I believe that a limited number of more universal human and material variables lie at the core of this infinite set' (5). In other words, it seems likely that what we do already understand about the more generalisable aspects of the ELE innovation management process, if taken into account, can make innovation in ELE more successful than it would otherwise be. This can perhaps be regarded as the chief value of the literature which has been reviewed here, and the primary rationale for its continuing development.

\section{Acknowledgements}

I am very grateful to Chris Kennedy, Numa Markee and Ron White, as well as several anonymous reviewers, for their very helpful feedback on earlier drafts of this article. I would also like to warmly thank the Editor, Graeme Porte, for his patience, flexibility and encouragement throughout, and Ewa Jaworska for her painstaking copy-editing.

\section{References}

Adamson, B. \& C. Davison (2008). English language teaching in Hong Kong primary schools: Innovation and resistance. In Murray (ed.), 11-25.

Adey, P. (2004). The professional development of teachers: Practice and theory. Dordretch: Kluwer.

Ajzen, I. (1988). Attitudes, personality and behavior. Milton Keynes: Open University Press.

Alderson, J. C. (1992). Guidelines for the evaluation of language education. In Alderson \& Beretta (eds.), 274-304.

Alderson J. C. (ed.) (2009). The politics of language education: Individuals and institutions. Bristol: Multilingual Matters.

Alderson J. C. \& A. Beretta (eds.) (1992). Evaluating second language education. New York: Cambridge University Press.

Allwright, D. \& R. Lenzuen (1997). Exploratory practice: Work at the Cultural Inglesa, Rio de Janeiro, Brazil. Language Teaching Research 1.1, 73-79.

Allwright D. \& A. Waters (eds.) (1994). Language in aid projects: Towards the year 2000. Lancaster University: Centre for Research in Language Education. [Colloquium proceedings]

Allwright, R. L. (1981). What do we want teaching materials for? ELT Fournal 36.1, 5-18.

Bax, S. (2003). CALL - past, present and future. System 31.1, 13-28.

Bennis W., K. D. Benne \& R. Chin (eds.) (1984). The planning of change (4th edn.). London: Holt, Rinehart and Winston. [1st edn. 1970, New York] 
Beretta, A. (1992). What can be learned from the Bangalore evaluation? In Alderson \& Beretta (eds.), 250-271.

Blackler, F. H. M. \& S. Shimmin (1984). Applying psychology in organizations. New York: Methuen.

Bowers, R. (1994). Towards 2000. In Allwright \& Waters (eds.), 118-123.

Bray, T. \& T. Luxon (1999). The role of baseline studies in ELT projects. In Kennedy (ed.), 32-39.

Breen, M. P., C. N. Candlin, L. Dam \& G. Gabrielsen (1989). The evolution of a teacher training programme. In R. K. Johnson (ed.), The second language curriculum. Cambridge: Cambridge University Press, 111-135.

Bridges, W. \& S. Mitchell (2000). Leading transitions: A new model for change. Leader to Leader 16 (Spring 2000), 30-36. http://www.leadertoleader.org/knowledgecenter/journal.aspx?ArticleID=28.

Buchanan, D. A. \& D. Boddy (1992). The expertise of the change agent: Public performance and backstage activity. New York: Prentice Hall.

Canagarajah, A. S. (1999). Resisting linguistic imperialism in English teaching. Oxford: Oxford University Press.

Capelle, R. G. (1979). Changing human systems. Toronto: International Human Systems Institute.

Carless, D. (1997). Managing systemic curriculum change: A critical analysis of Hong Kong's targetoriented curriculum initiative. International Review of Education 43.4, 349-366.

Carless, D. (1999). Large-scale curriculum change in Hong Kong. In Kennedy et al. (eds.), 19-28.

Carless, D. (2002). Implementing task-based learning with young learners. ELT fournal 56.4, 389-396.

Carter R. \& D. Nunan (eds.) (2001). The Cambridge guide to teaching English to speakers of other languages. Cambridge: Cambridge University Press.

Celani, A. (1994). Assessing the value of English for specific purposes programmes in national development. In Allwright \& Waters (eds.), 36-49.

Chin, R. \& K. Benne (1970). General strategies for effecting changes in human systems. In W. Bennis, K. D. Benne \& R. Chin (eds.), The planning of change. London: Holt, Rinehart and Winston, 32-59.

Clark, J. L. (1987). Curriculum renewal in school foreign language learning. New York: Oxford University Press.

Coleman, H. (1992). Moving the goalposts: Project evaluation in practice. In Alderson \& Beretta (eds.), 222-246.

Coleman H. (ed.) (1996). Society and the language classroom. Cambridge: Cambridge University Press.

Cooper, R. (1989). Language planning and social change. Cambridge: Cambridge University Press.

Crocker, A. (1987). Notes on project planning and implementation. Presented at a British Council workshop.

Crooks T. \& G. Crewes (eds.) (1995). Language and development. Denpasar, Bali: Indonesia Australia Language Foundation.

De Lano, L., L. Riley \& G. Crookes (1994). The meaning of innovation for ESL teachers. System 22.4, 487-496.

Donovan, P. (1998). Piloting - a publisher's view. In B. Tomlinson (ed.), Materials development in language teaching. Cambridge: Cambridge University Press, 149-189.

Edge J. (ed.) (2006). (Re-)locating TESOL in an age of empire. Basingstoke: Palgrave Macmillan.

Finney, D. (2002). The ELT curriculum: A flexible model for a changing world. In J. G. Richards \& W. A. Renandya (eds.), Methodology in language teaching: An anthology of current practice. Cambridge: Cambridge University Press, 69-79.

Fullan, M. (1998). Linking change and assessment. In Rea-Dickins \& Germaine (eds.), 253-262.

Fullan, M. (2001a). Leading in a culture of change. San Francisco, CA: Jossey-Bass.

Fullan, M. (2001b). The new meaning of educational change (3rd edn.). London: RoutledgeFalmer.

Fullan, M. \& S. Stiegelbauer (1991). The new meaning of educational change (2nd edn.). London: Cassell.

Godfrey, J., D. E. Murray, S. Nimmannit \& M. Wirth (2008). Teacher development in Thailand: Differing perspectives. In Murray (ed.), 138-154.

Goh, G. C. M. (1999). Nationwide curriculum innovation: How do we manage? In Kennedy et al. (eds.), 5-18.

Goh, C. C. M. \& M. Y. Tay (2008). Implementing the English language syllabus 2001 in Singapore schools: Interpretations and re-interpretations. In Murray (ed.), 85-107.

Hall, D. R. (1997). Why projects fail. In Kenny \& Savage (eds.), 258-267.

Hall, G. E. \& S. M. Hord (2001). Implementing change: Patterns, principles, and potholes. Boston, MA: Allyn and Bacon.

Handy, C. (1984). Taken for granted? Understanding schools as organizations. London: Longman \& Schools Council. 
Havelock, R. G. (1969). Planning for innovation through dissemination and utilization of knowledge. Ann Arbor, MI: Center for Research on Utilization of Scientific Knowledge Institute for Social Research the University of Michigan.

Hayes, D. (2000). Cascade training and teachers' professional development. ELT fournal 54.2, 135-145.

Henrichsen, L. E. (1989). Diffusion of innovations in English language teaching: The ELEC effort in Fapan, 1956-1968. New York: Greenwood Press.

Hlew, A. (1995). Counterpart training and sustainaibility: Effecting an exchange of skills. In Crooks \& Crewes (eds.), 76-82.

Hofstede, G. H. (1991). Cultures and organizations: Software of the mind. London: McGraw-Hill.

Holliday, A. (1992). Tissue rejection and informal orders in ELT projects: Collecting the right information. Applied Linguistics 13.4, 403-424.

Holliday, A. (1994a). Appropriate methodology and social context. Cambridge: Cambridge University Press.

Holliday, A. (1994b). The house of TESEP and the communicative approach: The special needs of state English language education. ELT Journal 48.1, 3-11.

Holliday, A. (1996a). Developing a sociological imagination: Expanding ethnography in international English language education. Applied Linguistics 17.2, 234-255.

Holliday, A. (1996b). Large- and small-class cultures in Egyptian university classrooms: A cultural justification for curriculum change. In Coleman (ed.), 86-104.

Holliday, A. (1999). Achieving cultural continuity in curriculum innovation. In Kennedy (ed.), 23-31.

Holliday, A. (2005). The struggle to teach English as an international language. Oxford: Oxford University Press.

Hollingworth, A. \& S. Spencer (1997). The shock of the new. In Kenny \& Savage (eds.), 74-87.

Howatt, A. (1984). A history of English language teaching. Oxford: Oxford University Press.

$\mathrm{Hu}, \mathrm{G}$. (2002). Potential cultural resistance to pedagogical imports: The case of communicative language teaching in China. Language, Culture and Curriculum 15.2, 93-105.

Huberman, A. M. (1973). Understanding change in education. Paris: Unesco.

Hutchinson, T. (1991). The management of change. The Teacher Trainer 5.3, 19-21.

Hutchinson, T. \& E. G. Hutchinson (1996). The textbook as agent of change. In T. Hedge \& N. Whitney (eds.), Power, pedagogy and practice. Oxford: Oxford University Press, 307-323.

Ingvarson, L., M. Meiers \& A. Beavis (2005). Factors affecting the impact of professional development programs on teachers' knowledge, practice, student outcomes \& efficacy. Education Policy Analysis Archives 13.10, 1-24.

Jackson, J., T. Piper \& N. Yildiz (1997). A Chinese initiative. In Kenny \& Savage (eds.), 178-190.

Karavas-Doukas, K. (1998). Evaluating the implementation of educational innovations: Lessons from the past. In Rea-Dickins \& Germaine (eds.), 25-50.

Katz, D., L. Byrkun \& P. Sullivan (2008). Challenges in translating change into practice: Textbook development in Ukraine. In Murray (ed.), 43-61.

Kelly, P. (1980). From innovation to adaptability: The changing perspective of curriculum development. In M. Galton (ed.), Curriculum change: The lessons of a decade. Leicester: Leicester University Press, 65-80.

Kennedy, C. (1987). Innovating for a change. ELT Journal 41.3, 163-170.

Kennedy, C. (1988). Evaluation of the management of change in ELT projects. Applied Linguistics 9.4, 329-342.

Kennedy, C. (1997). Training trainers as change agents. In I. McGrath (ed.), Learning to train: Perspectives on the development of language teacher trainers. Hemel Hempstead: Prentice Hall, 127-139.

Kennedy, C. (1999a). Introduction - learning to change. In Kennedy et al. (eds.), iv-viii.

Kennedy, C. (1999b). National change. In Kennedy et al. (eds.), 1-4.

Kennedy C. (ed.) (1999c). Innovation and best practice. Harlow: Longman.

Kennedy, G., P. Doyle \& G. [C. M.] Goh (eds.) (1999). Exploring change in English language teaching. Oxford: Macmillan.

Kennedy, C. \& J. Kennedy (1996). Teacher attitudes and change implementation. System 24.1, 351-360.

Kennedy, D. (1999). The foreign trainer as change agent and implications for teacher education programmes in China. In Kennedy et al. (eds.), 29-37.

Kennedy, J. \& C. Kennedy (1998). Levels, linkages, and networks in cross-cultural innovation. System $26.4,455-469$.

Kenny B. \& W. Savage (eds.) (1997). Language and development: Teachers in a changing world. Harlow: Longman. 
Keranen, N. (2008). A multi-theoretical approach to understanding and explaining research engagement by university ELT staff. Ph.D. thesis, Lancaster University.

Kinzley, S. (in progress). The impact of a university pre-sessional course on the academic writing behaviours of a group of Chinese undergraduate students studying for a degree in media and cultural studies. Ph.D. thesis, Lancaster University.

Klippel, F. (2008). New prospects or imminent danger? The impact of English medium instruction on education in Germany. In Murray (ed.), 26-42.

Kouraogo, P. (1987). Curriculum renewal and INSET in difficult circumstances. ELT fournal 41.3, $171-178$.

Krashen, S. D. \& T. D. Terrell (1988). The natural approach: Language acquisition in the classroom. Hemel Hempstead: Prentice Hall.

Kumaravadivelu, K. (2006). Dangerous liaison: Globalization, empire and TESOL. In Edge (ed.), $1-26$.

Lamb, M. (1995). The consequences of INSET. ELT fournal 49.1, 72-80.

Lambright, W. \& P. Flynn (1980). The role of local bureaucracy-centered coalitions. In J. Agnew (ed.), Innovation research and public policy. Syracuse, NY: Syracuse University Press.

Lamie, J. M. (2004). Presenting a model of change. Language Teaching Research 8.2, 115-142.

Lamie, J. M. (2005). Evaluating change in English language teaching. Basingstoke: Palgrave Macmillan.

Lee, K. W. (2007). An investigation of the implementation of the Malaysian 'SMART' school project. Ph.D. thesis, Lancaster University.

Li, D. (1998). 'It's always more difficult than you plan and imagine': Teachers' perceived difficulties in introducing the communicative approach in South Korea. TESOL Quarterly 32.4, 677-703.

Mackay, R., S. Wellesley, D. Tasman \& E. Bazergan (1998). Using institutional self-evaluation to promote the quality of language and communication training programmes. In Rea-Dickins \& Germaine (eds.), 111-131.

Malderez, A. \& C. Bodóczky (1999). Mentor courses: A resource book for trainer-trainers. Cambridge: Cambridge University Press.

Markee, N. (1992). The diffusion of innovation in language teaching. Annual Review of Applied Linguistics $13,229-243$.

Markee, N. (1997). Managing curricular innovation. Cambridge: Cambridge University Press.

Marpaung, M. P. \& T. Kirk (1997). Sustaining a project. In Kenny \& Savage (eds.), 241-257.

Marris, P. (1974). Loss and change. London: Routledge \& Kegan Paul.

Martin, W. M. \& L. P. Balabanis (1995). Team development of ELT projects: A case study. In Crooks \& Crewes (eds.), 16-30.

Mason, R. \& I. Mitroff (1984). A teleological power-oriented theory of strategy. In W. G. Bennis, K. D. Benne \& R. Chin (eds.), The planning of change (4th edn.). London: Holt, Rinehart \& Winston, 215-223.

Matsuda, A. (2006). Negotiating ELT assumptions in EIL classrooms. In Edge (ed.), 158-170.

McGovern, J. (1995). Changing paradigms: The project approach. In Crooks \& Crewes (eds.), 3-15.

Medgyes, P. (1994). Donor and recipient priorities. In Allwright \& Waters (eds.), 77-96.

Medgyes P. \& A. Malderez (eds.) (1996). Changing perspectives in teacher education. Oxford: Heinemann.

Morrow K. (ed.) (2005). Insights from the Common European Framework. Oxford: Oxford University Press.

Murni, D. \& S. Spencer (1997). Consultants and counterparts. In Kenny \& Savage (eds.), 218-230.

Murray, D. E. (2008a). Introduction. In Murray (ed.), 1-3.

Murray D. E. (ed.) (2008b). Planning change, changing plans: Innovations in second language teaching. Ann Arbor, MI: University of Michigan Press.

Nunan, D. (2003). The impact of English as a global language on educational policies and practices in the Asia-Pacific region. TESOL Quarterly 37.4, 589-613.

O'Sullivan, M. (2004). The reconceptualisation of learner-centred approaches: A Namibian case study. International Fournal of Educational Development 24.6, 585-602.

Parsons, C. \& B. Fidler (2005). A new theory of educational change - punctuated equilibrium: The case of the internationalisation of higher education institutions. British Fournal of Educational Studies $53.4,447-465$.

Pennycook, A. (1994). The cultural politics of English as an international language. London: Longman.

Prabhu, N. S. (1987). Second language pedagogy. Oxford: Oxford University Press.

Prapaisit de Segovia, L. \& D. M. Hardison (2009). Implementing education reform: EFL teachers' perspectives. ELT Journal 63.2, 154-162. 
Rea-Dickins P. \& K. P. Germaine (eds.) (1998a). Managing evaluation and innovation in language teaching: Building bridges. Harlow: Longman.

Rea-Dickins, P. \& K. P. Germaine (1998b). The price of everything and value of nothing: Trends in language programme evaluation. In Rea-Dickins \& Germaine (eds.), 3-24.

Richards, J. C. (1984). The secret life of methods. TESOL Quarterly 18.1, 7-23.

Richards, J. C. \& M. Pennington (1998). The first year of teaching. In J. C. Richards (ed.), Beyond training. Cambridge: Cambridge University Press, 173-190.

Roberts, J. (1998). Language teacher education: The reflective trainer. New York: Arnold.

Rogers, E. M. (1983). Diffusion of innovations (3rd edn.). New York: Free Press.

Rogers, E. M. (2003). Diffusion of innovations (5th edn.). New York: Free Press.

Rogers, E. M. \& F. F. Shoemaker (1971). Communication of innovations: A cross-cultural approach (2nd edn.). New York: Free Press.

Sakui, K. (2004). Wearing two pairs of shoes: Language teaching in Japan. ELT fournal 58.2, $155-163$.

Sanders J. R. (ed.) (1992). Evaluating school programs: An educator's guide. Newbury Park, CA: Corwin Press.

Scott, C. D. \& D. T. Jaffe (1990). Managing organisational change: A guide for managers. London: Kogan Page.

Shamim, F. (1996). Learner resistance to innovation in classroom methodology. In Coleman (ed.), $105-121$.

Skilbeck, M. (1982). Three educational ideologies. In T. Horton \& P. Raggat (eds.), Challenge and change in the curriculum. Sevenoaks: Hodder and Stoughton, 28-41.

Smith, H. (1995). Power and sustainability in language-related development projects. In Crooks \& Crewes (eds.), 65-75.

Smith, H. (1997). Donors and recipients. In Kenny \& Savage (eds.), 208-217.

Stoller, F. L. (1994). The diffusion of innovations in intensive ESL programs. Applied Linguistics 15.3, 300-327.

Tomlinson, B. (1988). In-service TEFL: Is it worth the risk? The Teacher Trainer 2.2, 17-19.

Tomlinson, B. (1990). Managing change in Indonesian high schools. ELT Journal 44.1, 25-37.

Trowler, P. R. (2003). Education policy (2nd edn.). London: Routledge.

Wall, D. (1996). Introducing new tests into traditional systems: Insights from general education and from innovation theory. Language Testing 13.3, 334-354.

Wall, D. (1999). The impact of high-stakes examinations on classroom teaching: A case study using insights from testing and innovation theory. Ph.D. thesis, Lancaster University.

Wall, D. (2000). The impact of high-stakes testing on teaching and learning: Can this be predicted or controlled? System 28.4, 499-509.

Wall, D. (2005). The impact of high-stakes examinations on classroom teaching: A case study using insights from testing and innovation theory. Cambridge: Cambridge University Press.

Wallace, M. J. (1991). Training foreign language teachers: A reflective approach. Cambridge: Cambridge University Press.

Waters, A. (1997). Managing ESP curriculum development. ESP Malaysia, 3.1, 1-11.

Waters, A. (2002). In-service teacher learning in ELT projects and programmes: An integrated approach. Ph.D. thesis, Lancaster University.

Waters, A. (2005). Expertise in teacher education: Helping teachers to learn. In K. Johnson (ed.), Expertise in second language learning and teaching. Basingstoke: Palgrave Macmillan, 210-229.

Waters, A. (2006). Facilitating follow-up in ELT INSET. Language Teaching Research 10.1, 32-52.

Waters, A. (2007). ELT and the spirit of the times. ELT fournal 61.4, 353-359.

Waters, A. (2009a). Advances in materials design. In M. H. Long \& C. J. Doughty (eds.), The handbook of language teaching. Oxford: Wiley-Blackwell, 311-326.

Waters, A. (2009b). Ideology in applied linguistics for language teaching. Applied Linguistics 30.1, 138143.

Waters, A. \& M. L. C. Vilches (2001). Implementing ELT innovations: A needs analysis framework. ELT Journal 55.2, 133-141.

Waters, A. \& M. L. C. Vilches (2008). Factors affecting ELT reforms: The case of the Philippines Basic Education Curriculum. RELC Journal 39.1, 5-24.

Watson Todd, R. (2006). Continuing change after the innovation. System 34.1, 1-14.

Wedell, M. (2003). Giving TESOL change a chance: Supporting key players in the curriculum change process. System 31.4, 439-456. 
Wedell, M. (2009). Planning for educational change - putting people and their contexts first. London: Continuum.

Weir, C. J. (1995). The role of insiders and outsiders in evaluating English language programmes and projects. In Crooks \& Crewes (eds.), 31-44.

Weir, C. J. \& J. T. Roberts (1994). Evaluation in ELT. Oxford: Blackwell.

West, M. A. \& J. L. Farr (1990). Innovation and creativity at work: Psychological and organizational strategies. New York: Wiley.

White, R. V. (1988). The ELT curriculum: Design, innovation, and management. Oxford: Blackwell.

White, R. V., M. Martin, M. Stimson \& R. Hodge (1991). Management in English language teaching. Cambridge: Cambridge University Press.

Widdowson, H. G. (1992). Innovation in teacher development. Annual Review of Applied Linguistics 13, 260-275.

Widdowson, H. G. (2000). On the limitations of linguistics applied. Applied Linguistics 21.1, 3-25.

Williams, M. \& R. Burden (1994). The role of evaluation in ELT project design. ELT Fournal 48.1, $22-27$.

Woodhall, M. (1994). Measuring the impact of aid projects. In Allwright \& Waters (eds.), 50-65.

Young, R. \& S. Lee (1984). EFL curriculum innovation and teachers' attitudes. In P. Larson, E. Judd \& D. Messerschmidt (eds.), On TESOL 1984: A brave new world of TESOL. Alexandria, VA: TESOL, 184-194.

Dr Alan Waters is a Senior Lecturer in the Department of Linguistics and English Language at Lancaster University, England. He has taught EFL and trained teachers in the UK and several other parts of the world and published a number of books and articles on a range of ELT topics. His main current research interests are in language teaching methodology, language teacher learning, and the management of innovation in language education. 